\title{
CFD simulation and validation of wind-driven rain on a building facade with an Eulerian multiphase model
}

\author{
A. Kubilay ${ }^{a, b, *}$, D. Derome ${ }^{a, b}$, B. Blocken ${ }^{c}$, J. Carmeliet ${ }^{a, b}$ \\ ${ }^{a}$ Chair of Building Physics, Swiss Federal Institute of Technology ETHZ, Zurich, Switzerland \\ ${ }^{b}$ EMPA, Swiss Federal Laboratories for Materials Testing and Research, Laboratory for Building Technologies, \\ Dübendorf, Switzerland \\ ${ }^{c}$ Building Physics and Services, Eindhoven University of Technology, Eindhoven, The Netherlands
}

* Corresponding author: Aytac Kubilay, Institute of Technology in Architecture, Chair of Building Physics, ETH Zurich, Wolfgang-Pauli-Strasse 15, CH-8093, Zurich, Switzerland. Tel.: +41 58765 4276; E-mail address: kubilay@arch.ethz.ch

\begin{abstract}
Wind-driven rain (WDR) is one of the most important moisture sources with potential negative effects on hygrothermal performance and durability of buildings. The impact of WDR on building facades can be understood in a better way by predicting the surface wetting distribution accurately. Computational Fluid Dynamics (CFD) simulation with the Lagrangian particle tracking (LPT) method has been widely used and validated by several researchers for different isolated building configurations. In this paper, Eulerian Multiphase modeling (EM) for WDR assessment is applied and validated for a monumental tower building (St. Hubertus building in The Netherlands). The LPT and EM models show comparable results and EM is validated by comparison of the calculated catch ratio values with available experimental data on windward facade. The deviations between the experimental and the model results at low rain intensity and wind speed are attributed to the absence of turbulent dispersion in both LPT and EM models. EM has the advantages, first, of less computational complexity and faster pre-processing and post-processing in terms of raindrop trajectories and WDR catch ratios, and second, of allowing the calculation of catch ratios on all surfaces of a complex geometry over the domain at once. The user time spent for the simulation decreases by at least a factor of 10 using EM instead of LPT for a single building. Additionally, the EM is expected to provide a sound basis for future WDR studies incorporating more accurate calculation of the wind flow field, e.g. by LES and the inclusion of turbulent dispersion.
\end{abstract}

Keywords: Driving rain, Wind-driven rain, Computational fluid dynamics (CFD), Eulerian multiphase model, Numerical simulation

\section{Introduction}

Wind-driven rain (WDR) is rain with a horizontal velocity component due to its co-occurrence with wind flow. The horizontal component of rain velocity leads to several phenomena in terms of building physics, such as surface soiling due to runoff, weathering, algae formation, salt damage and frost damage at exterior wall surfaces, and mold growth at inside wall surfaces [1, 2]. Moreover, several authors have indicated structural and performance problems in photovoltaic modules related to moisture ingress and degradation [3-5]. WDR is one of the most important moisture sources that influence the hygrothermal performance and the durability of building facades. With the forecasted climatic changes, more severe WDR exposure and increased maintenance requirements of buildings are expected [6]. The impinging WDR intensity is governed by several parameters, such as building geometry, environment topography, position on the building facade, wind speed, wind direction, rainfall intensity, and raindrop-size distribution [7]. WDR surface wetting information is used as a main boundary condition in building envelope heat-air-moisture (BE-HAM) transport models, reinforcing the need for accurate information on the spatial distribution of surface wetting.

Three methods exist for estimating the WDR load on building surfaces: (1) measurements, (2) semi-empirical methods, and (3) numerical simulation with Computational Fluid Dynamics (CFD). Blocken and Carmeliet [1, 2] provided an extensive review of WDR research in building science. Generally, measurements are difficult, timeconsuming and prone to errors [8-10]. They are also confined to the meteorological conditions present at the time of experiments and are case-specific. Semi-empirical methods on the other hand are fast and easy to use but they only give approximations and they cannot provide detailed information. For example, in the ISO Standard for WDR [11, 12], the mutual influence of buildings on WDR load is taken into account by a simplified reduction factor, called the obstruction factor. Blocken et. al. [13] showed that there may be cases where particular parts of the building are actually exposed to a higher amount of WDR due to the influence of another building, contrary to what the obstruction factor would estimate. Therefore, semi-empirical methods are generally reliable only for stand-alone buildings in simple configurations, or for preliminary analysis. These methods will not give accurate results in cases where complex flows around buildings due to the influence of the surrounding buildings are observed. Furthermore, both measurements and semi-empirical techniques are limited in terms of spatial detail and resolution. As a result, the 
moisture source due to WDR is often considered uniform across large parts of the facade. This in turn may lead to large errors in moisture transport simulations, as in reality, WDR loading is far from uniform across the facade.

CFD simulations can be a valuable alternative to measurements and semi-empirical methods. Although CFD simulations are often complex and time consuming, they can be used to obtain accurate spatial and temporal information on WDR. Blocken et al. [14] and Moonen et al. [15] provide an overview of applications of CFD in urban physics and building performance simulations. Blocken et al. [16] compared two different semi-empirical models with CFD simulations for two case studies, for which full-scale measurements were available. The agreement between measurements and CFD was found to be quite good with an average discrepancy of $20-25 \%$. On the other hand, the results predicted by semi-empirical models provided discrepancies up to a factor of 2 to 5 . The vast majority of CFD simulations of WDR impingement in the past was based on the steady-state numerical solution technique developed by Choi [17-20], which is based on a combined application of the 3D steady Reynolds Averaged Navier Stokes (RANS) equations (often with a k- $\varepsilon$ model) and Lagrangian Particle Tracking (LPT). Blocken and Carmeliet [7] extended Choi's simulation technique by adding the temporal component, allowing the determination of both the spatial and temporal distribution of WDR for transient rain events. This approach was further validated with full-scale measurements on the windward facade of isolated buildings [7, 21-26].

However, certain deficiencies of RANS k- $\varepsilon$ modeling around the windward facade edges and in the wake of the buildings have been reported [27-30], such as the size of the wake and the location of reattachment. Furthermore, LPT models in the literature usually neglect turbulent dispersion, which becomes important in regions or rain events where wind velocity is low and/or flowing parallel to the facade. This is why validation studies have mostly focused only on the windward facade of simple isolated buildings and mainly on the rain events where turbulent dispersion is less important. Recently, Blocken et al. [13] compared the standard k- $\varepsilon$ model, the Renormalisation Group (RNG) k- $\varepsilon$ model, the realizable $k-\varepsilon$ model, and the Reynolds stress model (RSM) with wind-tunnel measurements using three different building geometries. The comparison indicated that RSM provided accurate results compared to the other models, however, it still lacked the desired accuracy due to the deficiencies of RANS modeling. Thus, Detached Eddy Simulation (DES) or Large Eddy Simulation (LES) is suggested in order to achieve accurate results in more complex geometries, such as street canyons and actual urban environments. Similarly, Tominaga et al. [29] showed that reattachment length behind a single building is reproduced in a much better way by LES computations compared to various $\mathrm{k}-\varepsilon$ models.

The LPT model requires particle tracking for thousands of raindrops on a fine computational grid to achieve accurate results $[23,24]$. The user has to carefully define the raindrop injection positions, for every single raindrop diameter, in such a way that they cover the entire facade. This has to be repeated for different values of reference wind speed and reference wind direction. In addition, the trajectories need to be calculated with very small time or length steps for accurate results in regions of large flow gradients. As a result, all steps of LPT, i.e. pre-processing, solving and postprocessing, are very time consuming. This holds primarily for (valuable) user time, and only to a lesser extent for the actual calculation time. As long as the calculated wind-flow pattern is in steady-state, the pathlines of raindrops will not intersect each other. This is the necessary condition for the LPT model to calculate the catch ratios by conservation of mass through the stream-tube (see Fig. 1). However, this approach is not valid if the LPT model is combined with DES/LES to study the transient rain behavior. As a consequence, a transient study of the rain phase with LES modeling would require a very high number of raindrop injections. Then the catch ratios would have to be calculated by counting the number of trajectories that hit the facade. LPT model would have serious drawbacks given that LES is already computationally expensive. Eulerian Multiphase (EM) modeling can be a more convenient method because it allows overcoming the deficiencies of the LPT method. Recently, it has been shown that EM with RANS modeling gives encouraging results in terms of WDR calculations on the windward facade of an isolated low-rise building [31]. However, EM has still to be validated for other building geometries before implementing new functionalities into the model. This paper presents a WDR study with EM model on a monumental tower building and discusses its advantages over the LPT model.

In this paper, CFD simulation of WDR using 3D steady RANS with the EM model is performed and a validation with full-scale measurements is completed. For the validation study, the measurements by Briggen et al [25] on the Hunting Lodge St. Hubertus are chosen, as these data sets take into account the guidelines by Blocken and Carmeliet for accuracy in WDR measurements $[9,10]$ providing in-situ data with minimum measurement errors. The predictions of WDR surface wetting using the EM model are also compared with the available numerical results in [25] that were obtained using LPT. RANS with standard $k-\varepsilon$ model is used to calculate the wind-flow around the building. The results shown in this work are an intermediate step towards more accurate calculations combining LES and EM. Section 2 presents the governing equations and boundary conditions used in this study and explains how the WDR catch ratio is obtained from the simulations. In section 3 , the building geometry and the measurements used in the validation study are presented. The computational setup and the settings for the numerical simulation are given in section 4 . In section 5 , the results of the CFD WDR simulations are given and the validation study is conducted. Finally, section 6 and 7 provide a general discussion and conclusion, respectively. 


\section{Methodology}

The most common method in the literature to predict WDR impingement on buildings is based on the extension of Choi's steady state WDR approach [18, 19] into the time domain by Blocken and Carmeliet [7, 32]. In this approach, the rain phase is solved with LPT in a one-way coupled fashion, with the effect of raindrops on the fluid flow ignored. This extended method consists of following five steps:

a. The steady-state wind-flow pattern around the building is calculated based on the 3D steady RANS equations with a turbulence model for closure.

b. Raindrop trajectories are obtained by injecting raindrops of different sizes in the calculated wind-flow pattern and by solving their equations of motion.

c. The specific catch ratio for each raindrop size is determined based on the calculated raindrop trajectories.

d. The catch ratio is calculated from the specific catch ratio and the horizontal raindrop size distributions.

e. Experimental data records for wind speed, wind direction, and horizontal rainfall intensity during a certain rain event are combined with catch ratio charts to obtain the spatial and temporal distribution of WDR on the building facade.

Steps (b) and (c) involve a time consuming iterative "trial and error" procedure in order to find appropriate injection positions for the raindrops so that they cover the entire facade surface. It is important to note that this procedure needs to be repeated for every single combination of: (1) raindrop size, (2) reference wind speed, and (3) reference wind direction in order to establish a complete catch ratio chart for every position at the facade [7]. As an illustration, considering 15 classes of raindrop diameters $(0.3 \mathrm{~mm}-6 \mathrm{~mm}), 10$ values of reference wind speed $(1-15 \mathrm{~m} / \mathrm{s})$ and 12 wind directions yields 1800 separate trial and error procedures, which is very time-consuming. This explains why previous studies based on the LPT method have mostly considered only a limited number of raindrop diameters, reference wind speed values and only a few wind directions. Indeed, many studies have only focused on one wind direction, i.e. the one perpendicular to the main facade [7, 23-25]. On the other hand, with the EM model, to preprocess, solve, and post-process the WDR calculations is a much easier and faster procedure even for a domain consisting of a single building. This advantage is even more pronounced in situations of complex geometry with more than one building present.

In EM, the rain phase is regarded a continuum as is the wind phase. Each class of raindrop size is treated as a different phase, as each group of raindrops with similar size will interact with the wind-flow field in a similar way. Using the EM model, a boundary condition is imposed for each rain phase along the inlet boundaries, thus there is no need of positioning an injection plane into the correct position. Then, similarly to what is done in LPT, the WDR impingement is calculated with a summation over all classes of raindrop sizes on all building facades at once. Furthermore, it is possible to implement transient simulations using EM in an easier way. The governing equations of the EM approach are detailed in the next section.

\subsection{Governing equations}

2.1.1. Wind phase

3D Steady RANS with the standard k- $\varepsilon$ model [33] is used for wind-flow calculations in the present study by the following equations:

$$
\begin{aligned}
& \frac{\partial u_{j}}{\partial x_{j}}=0 \\
& \frac{\partial \rho_{a} u_{i}}{\partial t}+\frac{\partial\left(\rho_{a} u_{i} u_{j}\right)}{\delta x_{j}}=-\frac{\partial p}{\partial x_{i}}+\frac{\partial \tau_{i j}}{\delta x_{j}} \\
& \frac{\partial \rho_{a} k}{\partial t}+\frac{\partial\left(\rho_{a} k u_{j}\right)}{\partial x_{j}}=\frac{\partial}{\partial x_{j}}\left[\left(\mu+\frac{\mu_{t}}{\sigma_{k}}\right) \frac{\partial k}{\partial x_{j}}\right]+G_{k}-\rho_{a} \varepsilon \\
& \frac{\partial \rho_{a} \varepsilon}{\partial t}+\frac{\partial\left(\rho_{a} \varepsilon u_{j}\right)}{\partial x_{j}}=\frac{\partial}{\partial x_{j}}\left[\left(\mu+\frac{\mu_{t}}{\sigma_{\varepsilon}}\right) \frac{\partial \varepsilon}{\partial x_{j}}\right]+C_{1 \varepsilon} \frac{\varepsilon}{k} G_{k}-C_{2 \varepsilon} \rho_{a} \frac{\varepsilon^{2}}{k} \\
& \mu_{t}=C_{\mu} \rho_{a} \frac{k^{2}}{\varepsilon}
\end{aligned}
$$

where $\rho_{a}$ denotes the density of air, $p$ the pressure, $\tau_{i j}$ the Reynolds stresses, $k$ the turbulent kinetic energy, $\varepsilon$ the turbulence dissipation rate, $\mu$ the dynamic laminar viscosity of air, $\mu_{t}$ the dynamic turbulent viscosity of air, $\sigma_{k}$ the turbulent Prandtl number for $\mathrm{k}, \sigma_{\varepsilon}$ the turbulent Prandtl number for $\varepsilon, G_{k}$ the generation of turbulent kinetic energy due to mean velocity gradients, $C_{\mu}, C_{1 \varepsilon}$ and $C_{2 \varepsilon}$ are constants. The following model constants are used in 
the present study: $C_{1 \varepsilon}=1.44, C_{2 \varepsilon}=1.92, C_{\mu}=0.09, \sigma_{k}=1.0, \sigma_{\varepsilon}=1.3$. In the k- $\varepsilon$ model, the Reynolds stresses are modeled using turbulent viscosity, $\mu_{t}$, which is assumed to be an isotropic quantity. Therefore, the error increases in regions where anisotropic turbulent effects become relatively large.

Raindrop calculations are one-way coupled with the wind-flow. This is a valid assumption as the volumetric ratio of rain in air is below $1 \times 10^{-4}$ [31]. Turbulent dispersion is neglected in this study. In section 6 , it is discussed that the turbulent dispersion can be incorporated much more easily in the EM model than in the LPT model.

\subsubsection{Rain phase}

Mass and momentum conservation equations for the rain phase are solved by taking each class of raindrop size as a different phase. The governing equations for each rain phase are as described below:

$$
\begin{aligned}
& \frac{\delta \rho_{w} \alpha_{k}}{\delta t}+\frac{\delta\left(\rho_{w} \alpha_{k} u_{k j}\right)}{\delta x_{j}}=0 \\
& \frac{\delta \rho_{w} \alpha_{k} u_{k i}}{\delta t}+\frac{\delta\left(\rho_{w} \alpha_{k} u_{k i} u_{k j}\right)}{\delta x_{j}}=\rho_{w} \alpha_{k} g+\rho_{w} a_{k} \frac{3 \mu}{\rho_{w} d^{2}} \frac{C_{d} \operatorname{Re}_{R}}{4}\left(u_{i}-u_{k i}\right)
\end{aligned}
$$

where $d$ is the raindrop diameter, $\alpha_{k}$ is the volume fraction of $\mathrm{k}^{\text {th }}$ phase of rain, $u_{k i}$ the velocity component of $\mathrm{k}^{\text {th }}$ phase of rain, $u_{i}$ the velocity component of wind, $\rho_{w}$ the density of the raindrops, $g$ the gravitational acceleration, $C_{d}$ the drag coefficient. $\operatorname{Re}_{R}$ denotes the relative Reynolds number and is calculated as follows:

$$
\operatorname{Re}_{R}=\frac{\rho_{a} d}{\mu} \vec{u}-\overrightarrow{u_{k}}
$$

where $\vec{u}$ is the wind phase velocity vector, and $\overrightarrow{u_{k}}$ is the rain phase velocity vector.

\subsection{WDR parameters}

The calculation of the rain phase volumetric ratio and velocity fields allows obtaining the specific catch ratio, $\eta_{d}(k)$, and catch ratio, $\eta$, by the following equations:

$$
\begin{aligned}
& \eta_{d}(k)=\frac{R_{w d r}(k)}{R_{h}(k)}=\frac{\alpha_{k}\left|V_{n}(k)\right|}{R_{h} f_{h}(k)} \\
& \eta=\int_{d} f_{h}\left(R_{h}, d\right) \eta_{d} \mathrm{~d} d
\end{aligned}
$$

where $R_{w d r}$ denotes the WDR intensity, $R_{h}$ the horizontal rain intensity through the horizontal plane, $f_{h}\left(R_{h}, d\right)$ the raindrop size distribution through the horizontal plane [1] and $\left|V_{n}(k)\right|$ the velocity magnitude of the rain phase in the direction normal to the building facade.

In the present study, the raindrop size distribution through the horizontal plane (see Fig. 7) is based on the work of Best [34]. This work was based on a wide bibliographical survey and measurements for a large number of rain event at various locations.

\section{Building geometry and measurement data}

\subsection{Building geometry}

Fig. 2 shows the monumental tower of the Hunting Lodge St. Hubertus building and the positions of WDR gauges positioned on the tower. The building consists of a rectangular lower part with wings and a tower with a height of 34.5 $\mathrm{m}$. The tower has a rectangular floor plan with dimensions of $4.8 \times 4.2 \mathrm{~m}^{2}$, and has a pitched roof. The building is located at the northern side of the Dutch National Park 'De Hoge Veluwe", Iongitude $52^{\circ} 07^{\prime}$ and latitude $5^{\circ} 49^{\prime}$, at approximately $42 \mathrm{~m}$ above sea level. There are no other buildings in the immediate vicinity of the Hunting Lodge. The aerial view of the surrounding area shows that the terrain is also more open facing the south-west direction of the building (see Fig. 3). The building is surrounded by a forest in other directions. 


\subsection{Measurement data}

The measurements and the WDR simulation using the LPT model were performed by Briggen et al. [25]. The measurements of reference wind speed, wind direction, and horizontal rainfall intensity were recorded at a meteorological station, located the north-west of the building. The station was positioned between the forest and the building in such a way that south-west wind is measured with minimum disturbance. The weather station was equipped with an ultrasonic anemometer, which provided measurements of the reference wind speed and the reference wind direction at a height of $10 \mathrm{~m}$. The horizontal rainfall intensity was measured by a tipping bucket rain gauge with a horizontal orifice.

The WDR measurements were conducted with WDR gauges that contain a tipping bucket mechanism. The WDR gauges have six times higher resolution than the standard rain gauges. Most of the WDR gauges were located on the south-west facade of the tower, as this facade showed severe moisture-related deterioration due to the prevailing south-west wind direction during rain events. Thus, the study of Briggen et al. [25] and the present study consider mainly rain events with south-west wind direction.

Fig. 4(a) and (b) show the rain events measured by Briggen et al. [25] on September $17^{\text {th }}, 2007$ and September $25^{\text {th }}$, 2007 , respectively. The measurement errors in terms of catch ratio are given as 0.022 , leading to errors of between $9.2 \%-27.5 \%$, for the measurements on September $17^{\text {th }}$, and as 0.011 , leading to errors of between $2.7 \%-5.3 \%$, for the measurements on September $25^{\text {th }}$. The error estimates are lower for the measurements on September $25^{\text {th }}$ as there are few dry periods between rain showers during which adhesion-water-evaporation can occur on the rain collector [10]. The wind direction is almost constant and nearly south-west $\left(225^{\circ}\right.$ from north) for both rain events. This results in very limited amount of WDR impingement on the lateral facades due to the fluctuations in the wind direction. The wind direction in the simulations is thus perpendicular to the facade of interest on the tower, avoiding some of the deficiencies of RANS modeling.

\section{Numerical simulation: settings and parameters}

The calculation procedure is based on the technique introduced by Blocken and Carmeliet [7], but the present authors use the EM model for WDR. In this technique, in order to reduce the computational expense to model a long rain event, the rain event is discretized into 1-minute or 10-minute time steps. CFD simulations are only made for a limited number of horizontal rainfall intensity $R_{h}$ and wind speed $U_{10}$ couples. Each time step with a certain $\left(R_{h}, U_{10}\right)$ couple is assumed to be in steady-state and simulations were run for a certain number of reference wind speed and reference rainfall intensity values. Following this step, it is possible to obtain a catch ratio distribution on the building surfaces for a certain rain event by linear interpolation of the catch ratio values calculated from reference couples. In this study, the following steps have been followed:

a. The wind-flow field around the building is solved for $U_{10}=10 \mathrm{~m} / \mathrm{s}$. The wind-flow field for other values of the reference wind speed $\left(U_{10}=1,2,3,5 \mathrm{~m} / \mathrm{s}\right)$ are obtained by linear scaling. Such scaling is allowed for flows around sharp-edged bluff bodies, where the positions of flow separation are independent of the Reynolds number.

b. Using each reference wind-flow field, specific catch ratio distributions are calculated for several raindrop diameter values (diameters ranging from 0.5 to $1 \mathrm{~mm}$ in steps of $0.1 \mathrm{~mm}$, from 1 to $2 \mathrm{~mm}$ in steps of $0.2 \mathrm{~mm}$, and from 2 to 6 $\mathrm{mm}$ in steps of $1 \mathrm{~mm}$ ).

c. Catch ratio distributions are obtained for a list of reference horizontal rainfall intensities of $R_{h}=0,0.1,0.5,1,2,3,4$ $5,6,8,10,12,15,20,25$, and $30 \mathrm{~mm} / \mathrm{h}$ using the droplet size distribution as input (see section 4.2.2).

$\mathrm{d}$. The catch ratio for the rain event is obtained by summation over all the time steps in the rain event by the following relation:

$\eta=\frac{\sum_{t_{i}} \eta\left(t_{i}\right) S_{h}\left(t_{i}\right)}{\sum_{t_{i}} S_{h}\left(t_{i}\right)}$

where $S_{h}\left(t_{i}\right)$ is the horizontal rainfall amount for the timestep $t_{i}$.

\subsection{Computational domain}

The computational domain has dimensions $L \times B \times H=350 \times 350 \times 205 \mathrm{~m}^{3}$, as shown in Fig. 5. The blockage ratio of the domain is about $0.7 \%$ and the distance of the building from the domain boundaries satisfies the guidelines stated in Tominaga et al. [30] and Franke et al. [35]. The same grid, which was selected by a grid independence study by Briggen et al, is used for the sake of comparison of the results from both methods [25]. The grid is unstructured with 650,000 tetrahedral cells, as shown in Fig. 6. 
4.2. Boundary conditions

4.2.1. Wind phase

The vertical profiles of mean wind speed, $U$, turbulent kinetic energy, $\mathrm{k}$, and turbulence dissipation rate, $\varepsilon$, imposed at the inlet boundary represent the roughness characteristics of the upstream terrain. As for the grid, the inlet boundary conditions in Briggen et al. [25] are used for the sake of comparison. The inlet profile of mean wind speed is defined with the typical log-law expression:

$U(y)=\frac{u_{A B L}^{*}}{\kappa} \ln \left(\frac{y+y_{0}}{y_{0}}\right)$

where $U(y)$ denotes the mean streamwise wind speed at height y above the ground plane, $u_{A B L}^{*}$ the $\mathrm{ABL}$ friction velocity, $\kappa$ the von Karman constant ( 0.42 in the present study), and $y_{0}$ the aerodynamic roughness length. In the present study, an aerodynamic roughness length of 1.0 is chosen, which represents a landscape totally and quite regularly covered with similar-size large obstacles, with open spaces comparable to the obstacle heights, e.g. mature regular forests, homogeneous cities or villages, according to the Davenport roughness classification [36]. Note that a fetch distance of about $10 \mathrm{~km}$ is required to determine the correct $y_{0}$, as the internal boundary layers develop

gradually depending on the changes in surface roughness. The ABL friction velocity, $u_{A B L}^{*}$, is chosen such that the desired reference wind speed, $U_{10}$, at a height of $10 \mathrm{~m}$ is obtained.

The inlet profiles of turbulent quantities are defined by the following expressions:

$$
\begin{aligned}
& k(y)=\left(I_{u} U(y)\right)^{2} \\
& \varepsilon(y)=\frac{u_{A B L}^{* 3}}{\kappa\left(y+y_{0}\right)}
\end{aligned}
$$

where $I_{u}$ denotes the streamwise turbulence intensity. $I_{u}$ is taken $31 \%$ at a height of $2 \mathrm{~m}$ and $8 \%$ at the top of the domain in this study.

For the ground surface treatment, the standard wall functions by Launder and Spalding [37], with appropriate roughness modification [38], are used. The equivalent sand-grain roughness height ( $\left.k_{s}\right)$ is kept constant, and the roughness constant $\left(C_{s}\right)$ is modified for regions surrounding the building using the following expression [39]:

$k_{s}=\frac{9.793 y_{0}}{C_{s}}$

A constant static pressure of $0 \mathrm{~Pa}$ is used at the outlet boundary. Symmetry conditions are applied at the top and on both sides of the domain.

\subsubsection{Rain phase}

Instead of specifying an injection plane consisting of injection positions for every single raindrop as in the LPT model, appropriate boundary conditions are set for the rain phase volumetric fractions and velocities at the computational domain boundaries.

With the definitions established in section 2.2 , the volumetric ratio of rain phase $\mathrm{k}$ can be calculated as:

$\alpha_{k}=\frac{R_{h} f_{h}\left(R_{h}, d\right)}{V_{t}(d)}$

where $V_{t}(d)$ represents the terminal velocity of fall of a raindrop with diameter $d$. The raindrop size distribution through a horizontal plane is shown in Fig. 7. The terminal velocity measurements were studied by Gunn and Kinzer [40] and shown in Fig. 8. The implemented drag coefficients should be in agreement with the terminal velocity data, otherwise some artificial acceleration towards the ground can be experienced during simulations even in regions with undisturbed flow field with zero vertical component. Drag coefficients, which were measured by Gunn and Kinzer [40], take into account changes in the shape of falling raindrops. 
The value of volumetric ratio of $\mathrm{k}^{\text {th }}$ phase, $\alpha_{k}$, is imposed at the inlet and top boundaries. For the rain phase velocity, $u_{k}$, it is assumed that the boundaries are undisturbed and far away from the object in the domain. The rain phase velocity component along the direction of gravitational acceleration is set equal to the terminal velocity of fall for that phase. The rain phase velocity components perpendicular to the direction of gravitational acceleration are set equal to the wind phase velocity components, so that the relative velocity between wind and rain is zero at the boundary.

The boundary conditions for the rain phases at the building walls, on the ground and at the outlet are set in such way that the normal gradient of the volumetric ratio, $\delta \alpha_{k} / \delta n$, equals zero when the normal wind velocity vector is pointing out of the domain, and the values of the volumetric ratio, $\alpha_{k}$, are equal to zero when the normal wind velocity vector is pointing into the domain. With these boundary conditions, the interaction between the raindrops and the walls are not modeled and the raindrops leave the domain as soon as they hit a wall boundary, avoiding any inflow of rain phase into the domain due to possible recirculation regions. The summary of the boundary conditions and the parameters used for the rain phase equations can be found in Table 1.

\subsection{Solution strategy}

OpenFOAM ${ }^{\circledR} 2.0$ is used in this study as the CFD code. It is an open-source, implicit, segregated, and double precision solver. The pressure-velocity coupling for the wind flow field solution is taken care of with the Semi-Implicit Method for Pressure Linked Equations (SIMPLE) algorithm. An additional solver is implemented into the code by the author for solving the governing equations of the EM model. This solver gives the rain phase velocity, volumetric ratio, and specific catch ratio distributions in a one-way coupled fashion.

\subsection{Horizontal inhomogeneity}

Due to the inconsistencies between the inlet wind profile, wall functions, grid, and turbulence model, problem of horizontal inhomogeneity can occur. Horizontal inhomogeneity refers to the occurrence of streamwise gradients in the vertical profiles of mean wind speed, turbulent kinetic energy and turbulence dissipation rate, as they travel through the computational domain, from the inlet plane towards the position where the buildings are located. Richards and Hoxey [41] and Blocken et al. [39] reported these problems and provided effective remedial measures for $y_{0}$-type and $\mathrm{k}_{\mathrm{s}}$-type wall functions, respectively. In addition, Blocken et al. [42] showed the important consequences that horizontal inhomogeneity can have on the accuracy of CFD simulation results. In the present study, horizontal homogeneity is particularly required to ensure that the inlet profile, which represents the wind speed values measured at a weather mast stationed near the building, remains the same. However, due to the restrictions on the placement of the inlet boundary, the inlet profile is imposed at a certain distance from the tower in the computational domain, in this case about $150 \mathrm{~m}$. In Fig. 9, the vertical wind speed profiles for the inlet flow and incident flow conditions are compared. The incident flow profile is obtained in an empty computational domain at the position where the building would be located [39]. The highest error between incident and inlet flow quantities is $2.7 \%$. Thus, horizontal inhomogeneity is considered insignificant. Note that the discretized inlet flow profile differs slightly from the arithmetic values given by Eq. (12) due to the unstructured type of the grid and the relatively coarse grid resolution at the inlet plane.

\section{Numerical simulation: results and validation}

\subsection{Wind-flow and WDR patterns}

Fig. 10(a) shows the mean wind speed and direction in the vertical mid-plane through the building. Typical flow features as the standing vortex, the down-flow from the stagnation point, large vortices behind the building, and flow restoration behind the building are visible. Fig. 10(b) shows the mean wind speed and direction in the horizontal plane of $y=8 \mathrm{~m}$. A low velocity region exists behind the tower, which shows out-of-the-plane vectors that correspond to the large vortex seen in Fig. 10(a).

The WDR catch ratio simulations provide a matrix of results for 80 couples of different reference wind speeds and reference horizontal rainfall intensities (see an example in Fig. 11). This catch ratio chart can be used to calculate the catch ratio distribution for any rain event - as long as the reference wind direction is south-west, as there are no other wind direction calculations in the present study.

Fig. 12 shows the streamlines of the wind and rain phases for some selected reference wind speed values and raindrop sizes. Fig. 12(a),(c), and (e) show the streamlines for $U_{10}=3 \mathrm{~m} / \mathrm{s}$ and $d=0.5,1.0$, and $5.0 \mathrm{~mm}$,

respectively. Smaller raindrops at this low wind speed $(3 \mathrm{~m} / \mathrm{s})$ follow a more horizontal streamline and are more influenced by the local velocity field. Note that in Fig. 12(a) the raindrops travel downwards along a trajectory that is almost parallel to the tower facade near the lower parts, whereas in Fig. 12(e) the raindrops hit the windward facade at a smaller angle to the normal, similar at all locations. For the higher wind speed $(10 \mathrm{~m} / \mathrm{s}$ ) (see Fig. 12(b), (d), and (f)) the horizontal component of raindrop velocity is even larger and the differences in angle of attack can be hardly 
distinguished. Note that in Fig. 12(b), the upward acceleration of the raindrops near the roof is clearer compared to the other cases.

Fig. 13 shows the specific catch ratio distributions on the front facade of the tower for the combinations of reference wind speed and raindrop size shown in Fig. 12. Fig. 13(a),(c), and (e) show the specific catch ratio distributions for $U_{10}=3 \mathrm{~m} / \mathrm{s}$ and $d=0.5,1.0$, and $5.0 \mathrm{~mm}$, respectively. The vertical specific catch ratio gradient on the facade is larger for smaller raindrop sizes, as they are more influenced by the local wind flow patterns. Fig. 13(b),(d), and (f) show the specific catch ratio distributions for $U_{10}=10 \mathrm{~m} / \mathrm{s}$ and $d=0.5,1.0$, and $5.0 \mathrm{~mm}$, respectively. Note that the color scales are different for the cases with different reference wind speed values, $U_{10}$. The changes in vertical gradients are still similar to the previous case, but this time the specific catch ratio values are all higher with increasing wind speed.

Fig. 14(a) and (b) show the numerical results of the catch ratio distribution on the Hunting Lodge St. Hubertus building at the end of the rain events on September $17^{\text {th }}, 2007$ and September 25th, 2007, respectively. Note that, on the flat roofs, the catch ratio values are around 1 for both rain events, except where protected by a higher part of the building. The inclined roof of the tower has a smaller WDR load which is similar on both rain events. Near the front edges, there is a slight decrease in catch ratio due to the upward acceleration of wind velocity around those edges. This effect is clearer for the rain event on September $25^{\text {th }}$. Similarly, the catch ratio values are also lower at regions where separation flow is observed around the side edges.

\subsection{Validation}

Fig. 15(a) and (b) shows three sets of results on the windward facade of the tower at the end of the rain events on September $17^{\text {th }}$, and September $25^{\text {th }}$ : the measured values of the catch ratio at the end of the rain event, the simulated values of the catch ratio at the end of the rain event, using the LPT model [25] and the simulated values using the EM model. Note that in addition to simulated contour lines, the simulated values at the positions of the WDR gauges are explicitly indicated in text boxes for comparison purposes. At the higher positions of the facade, i.e. positions 2, 5, and 6 , the difference between numerical results and measurements is relatively low, considering the complex nature of WDR. However, at the lower positions, for the rain event on September $25^{\text {th }}$, there is a relatively large difference between numerical results and measurements. Note that the catch ratio results from EM model agree well with the calculations by LPT model by Briggen et al. [25]. Table 2 and Table 3 summarize the calculated catch ratio values with the measurement results and numerical results by Briggen et al. [25]. In both models, LPT and EM, RANS k- $\varepsilon$ modeling was used to simulate the wind flow field. As indicated before, RANS $k-\varepsilon$ modeling has several issues that may influence the wind flow and WDR results. However, the underprediction of WDR at position 4 at the bottom of the tower, where the streamlines of the rain phase are almost parallel to the facade (see Fig. 12(a)), can be attributed to the fact that both models neglect the turbulent dispersion phenomenon, as discussed by Briggen et al. [25]. Given the relatively low wind speed during the rain event (see Fig. 4(b)) and higher wind blocking effect of the tower compared to a low-rise building, turbulent dispersion becomes more important at the lower parts of the building. Moreover, the horizontal rainfall intensity values in the rain events are not quite high, which means the raindrop size distribution shifts to smaller raindrops (Fig. 7), which makes the blocking effect more prominent.

\section{Discussion}

Conservative estimates of the WDR catch ratio measurement error were 0.022 for the rain event on September $17^{\text {th }}$, and 0.011 for the rain event on September $25^{\text {th }}$ [25]. For the rain event on September $17^{\text {th }}$, the numerical values agree with the measurements quite well. However, for the rain event on September $25^{\text {th }}$, and especially at the lower part of the tower, the numerical results are lower than the measured data. According to Blocken and Carmeliet [7], the variation of specific catch ratio with raindrop size is limited to the smaller drop sizes, thus, the catch ratio plots are more sensitive to possible errors in the numerical model and/or the measurements for the rain events with low rainfall intensities. Furthermore, neglecting turbulent dispersion in the model might have led to an underestimation of the catch ratio at the lower part of the tower. On the other hand, it can be concluded that the present model is successful at reproducing the numerical results that were obtained by LPT.

One of the advantages of EM is the ease of applying the inlet boundary conditions and the reduction of complexity in calculation. The LPT model on the other hand involves the tedious task of specifying the raindrop injection locations for each building facade, reference wind speed, reference wind direction, and raindrop diameter to be studied. In EM modeling, the rain phase is simply defined as a volume ratio on the inlet boundary and the catch ratio is calculated over the building facade by integrating the variables. Furthermore, EM gives the WDR wetting distributions on all building facades in the model at once. The difference between LPT and EM in user time needed for a WDR simulation on the windward facade of an isolated building is about a factor of 10, and much larger when WDR on several buildings is studied. 
EM can be considered as an intermediate step towards the inclusion of a more accurate wind-flow model, such as LES, and the inclusion of turbulent dispersion into the model. Transient simulations, possibly LES, should be considered in order to include turbulent dispersion in the model. However, with transient simulations, the method based on steady-state stream-tubes that is used in LPT is no longer valid. This leads to a necessity of covering the building facade with a very large number of raindrop trajectories, which results in an even higher computational cost than EM would require. With this reason, EM can be a strong alternative for WDR simulations in urban context.

\section{Conclusions}

The study on the WDR catch ratio values using EM model during a rain event on the Hunting Lodge St. Hubertus building is presented. The catch ratio distribution is compared with the existing measurement results and the numerical results by LPT model [25]. Very good agreement has been found between two models in terms of catch ratio values on the windward facade. Validation with measurement data is good at higher parts of the tower, however the numerical model underestimates the catch ratio values at lower parts of the tower, where the wind speed is low and small droplets move almost parallel to the building. These discrepancies are attributed to the fact that turbulent dispersion is more important in such cases. EM model can be an easier way to include the turbulent dispersion into WDR calculations. Furthermore, it is possible to incorporate LES in EM modeling, which allows more accurate wind flow calculations including transient rain phase calculations. EM model allows a faster preprocessing than LPT, as EM simply consists of applying the rain phase inlet boundary conditions. A time gain factor of about 10 is reached for a single building facade. For studies involving more than one façade and/or building, e.g. an urban geometry, the time gain will be even more.

\section{Acknowledgements}

The research was supported through the Swiss National Science Foundation (SNF) - Project no. 135510. 


\section{References}

[1] Blocken B, Carmeliet J. A review of wind-driven rain research in building science. J Wind Eng Ind Aerodyn. 2004;92:1079-130.

[2] Blocken B, Carmeliet J. Overview of three state-of-the-art wind-driven rain assessment models and comparison based on model theory. Build Environ. 2010;45:691-703.

[3] Meyer EL, van Dyk EE. Assessing the reliability and degradation of photovoltaic module performance parameters. Reliability, IEEE Transactions on. 2004;53:83-92.

[4] Jorgensen GJ, Terwilliger KM, DelCueto JA, Glick SH, Kempe MD, Pankow JW, et al. Moisture transport, adhesion, and corrosion protection of PV module packaging materials. Solar Energy Materials and Solar Cells. 2006;90:2739-75.

[5] Kempe MD. Modeling of rates of moisture ingress into photovoltaic modules. Solar Energy Materials and Solar Cells. 2006;90:2720-38.

[6] Sanders $\mathrm{CH}$, Phillipson MC. UK adaptation strategy and technical measures: the impacts of climate change on buildings. Building Research \& Information. 2003;31:210-21.

[7] Blocken B, Carmeliet J. Spatial and temporal distribution of driving rain on a low-rise building. Wind Struct. 2002;5:441-62.

[8] Högberg A, Kragh M, van Mook FJR. A comparison of driving rain measurements with different gauges. 5th Symposium of Building Physics in the Nordic Countries. Göteborg (SE)1999. p. 361-8.

[9] Blocken B, Carmeliet J. High-resolution wind-driven rain measurements on a low-rise building - experimental data for model development and model validation. J Wind Eng Ind Aerodyn. 2005;93:905-28.

[10] Blocken B, Carmeliet J. On the accuracy of wind-driven rain measurements on buildings. Build Environ. 2006;41:1798-810.

[11] Sanders C. Heat, air and moisture transfer in insulated envelope parts. IEA Annex 24, Final report - Vol 2, Task 2: Environmental conditions Acco Leuven, Leuven, Belgium1996.

[12] CEN. DRAFT prEN ISO 15927-3. Hygrothermal performance of buildings - Calculation and presentation of climatic data - Part 3: Calculation of a driving rain index for vertical surfaces from hourly wind and rain data (ISO 15927-3:2009). 2006.

[13] Blocken B, Dezso G, van Beeck J, Carmeliet J. The mutual influence of two buildings on their wind-driven rain exposure and comments on the obstruction factor. J Wind Eng Ind Aerodyn. 2009;97:180-96.

[14] Blocken B, Stathopoulos T, Carmeliet J, Hensen JLM. Application of computational fluid dynamics in building performance simulation for the outdoor environment: an overview. Journal of Building Performance Simulation.

2011;4:157-84.

[15] Moonen P, Defraeye TWJ, Dorer V, Blocken B, Carmeliet J. Urban physics : effect of the microclimate on comfort, health and energy demand. Frontiers of Architectural Research. 2012.

[16] Blocken B, Abuku M, Nore K, Briggen PM, Schellen HL, Thue JV, et al. Intercomparison of wind-driven rain deposition models based on two case studies with full-scale measurements. J Wind Eng Ind Aerodyn. 2011;99:44859 .

[17] Choi ECC. Numerical simulation of wind-driven rain falling onto a 2-D building. Asia Pacific Conf on Computational Mechanics. Hong Kong1991. p. 1721-8.

[18] Choi ECC. Simulation of wind-driven-rain around a building. J Wind Eng Ind Aerodyn. 1993;46-47:721-9.

[19] Choi ECC. Determination of wind-driven-rain intensity on building faces. J Wind Eng Ind Aerodyn. 1994;51:55-69.

[20] Choi ECC. Modelling of wind-driven rain and its soil detachment effect on hill slopes. J Wind Eng Ind Aerodyn. 2002;90:1081-97.

[21] van Mook FJR. Driving rain on building envelopes. Eindhoven, The Netherlands: Eindhoven University of Technology; 2002.

[22] Tang W, Davidson Cl. Erosion of limestone building surfaces caused by wind-driven rain: 2. Numerical modeling. Atmospheric Environment. 2004;38:5601-9.

[23] Blocken B, Carmeliet J. The influence of the wind-blocking effect by a building on its wind-driven rain exposure. J Wind Eng Ind Aerodyn. 2006;94:101-27.

[24] Blocken B, Carmeliet J. Validation of CFD simulations of'wind-driven rain on a low-rise building facade. Build Environ. 2007;42:2530-48.

[25] Briggen PM, Blocken B, Schellen HL. Wind-driven rain on the facade of a monumental tower: Numerical simulation, full-scale validation and sensitivity analysis. Build Environ. 2009;44:1675-90.

[26] Abuku M, Blocken B, Nore K, Thue JV, Carmeliet J, Roels S. On the validity of numerical wind-driven rain simulation on a rectangular low-rise building under various oblique winds. Build Environ. 2009;44:621-32.

[27] Murakami S. Computational wind engineering. J Wind Eng Ind Aerodyn. 1990;36:517-38.

[28] Murakami S. Comparison of various turbulence models applied to a bluff-body. J Wind Eng Ind Aerodyn. 1993;467:21-36

[29] Tominaga Y, Mochida A, Murakami S, Sawaki S. Comparison of various revised k- $\varepsilon$ models and LES applied to flow around a high-rise building model with 1:1:2 shape placed within the surface boundary layer. J Wind Eng Ind Aerodyn. 2008;96:389-411. 
[30] Tominaga Y, Mochida A, Yoshie R, Kataoka H, Nozu T, Yoshikawa M, et al. AlJ guidelines for practical applications of CFD to pedestrian wind environment around buildings. J Wind Eng Ind Aerodyn. 2008;96:1749-61. [31] Huang SH, Li QS. Numerical simulations of wind-driven rain on building envelopes based on Eulerian multiphase model. J Wind Eng Ind Aerodyn. 2010;98:843-57.

[32] Blocken B, Carmeliet J. On the errors associated with the use of hourly data in wind-driven rain calculations on building facades. Atmospheric Environment. 2007;41:2335-43.

[33] Launder BE, Spalding DB. Lectures in mathematical models of turbulence London, New York: Academic Press; 1972.

[34] Best AC. The size distribution of raindrops. Quarterly Journal of the Royal Meteorological Society. 1950;76:16-36. [35] Franke J, Hellsten A, Schlunzen KH, Carissimo B. The COST 732 Best Practice Guideline for CFD simulation of flows in the urban environment: a summary. International Journal of Environment and Pollution. 2011;44:419-27.

[36] Wieringa J. Updating the Davenport roughness classification. J Wind Eng Ind Aerodyn. 1992;41:357-68.

[37] Launder BE, Spalding DB. The numerical computation of turbulent flows. Comput Methods Appl Mech Eng. 1990:269-89.

[38] Cebeci T, Bradshaw P. Momentum Transfer in Boundary Layers. New York: Hemisphere Publishing Corporation; 1977.

[39] Blocken B, Stathopoulos T, Carmeliet J. CFD simulation of the atmospheric boundary layer: wall function problems. Atmospheric Environment. 2007;41:238-52.

[40] Gunn R, Kinzer GD. The terminal velocity of fall for water droplets in stagnant air. Journal of Meteorology. 1949;6:243-8.

[41] Richards PJ, Hoxey RP. Appropriate boundary conditions for computational wind engineering models using the k$\epsilon$ turbulence model. J Wind Eng Ind Aerodyn. 1993;46-47:145-53.

[42] Blocken B, Carmeliet J, Stathopoulos T. CFD evaluation of wind speed conditions in passages between parallel buildings - effect of wall-function roughness modifications for the atmospheric boundary layer flow. J Wind Eng Ind Aerodyn. 2007;95:941-62. 


\section{Figures}

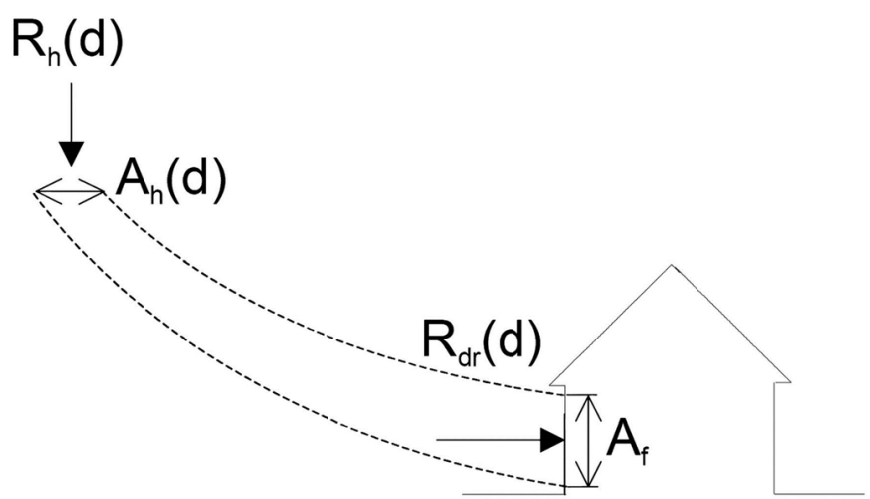

Fig. 1. Stream tube bounded by raindrop trajectories

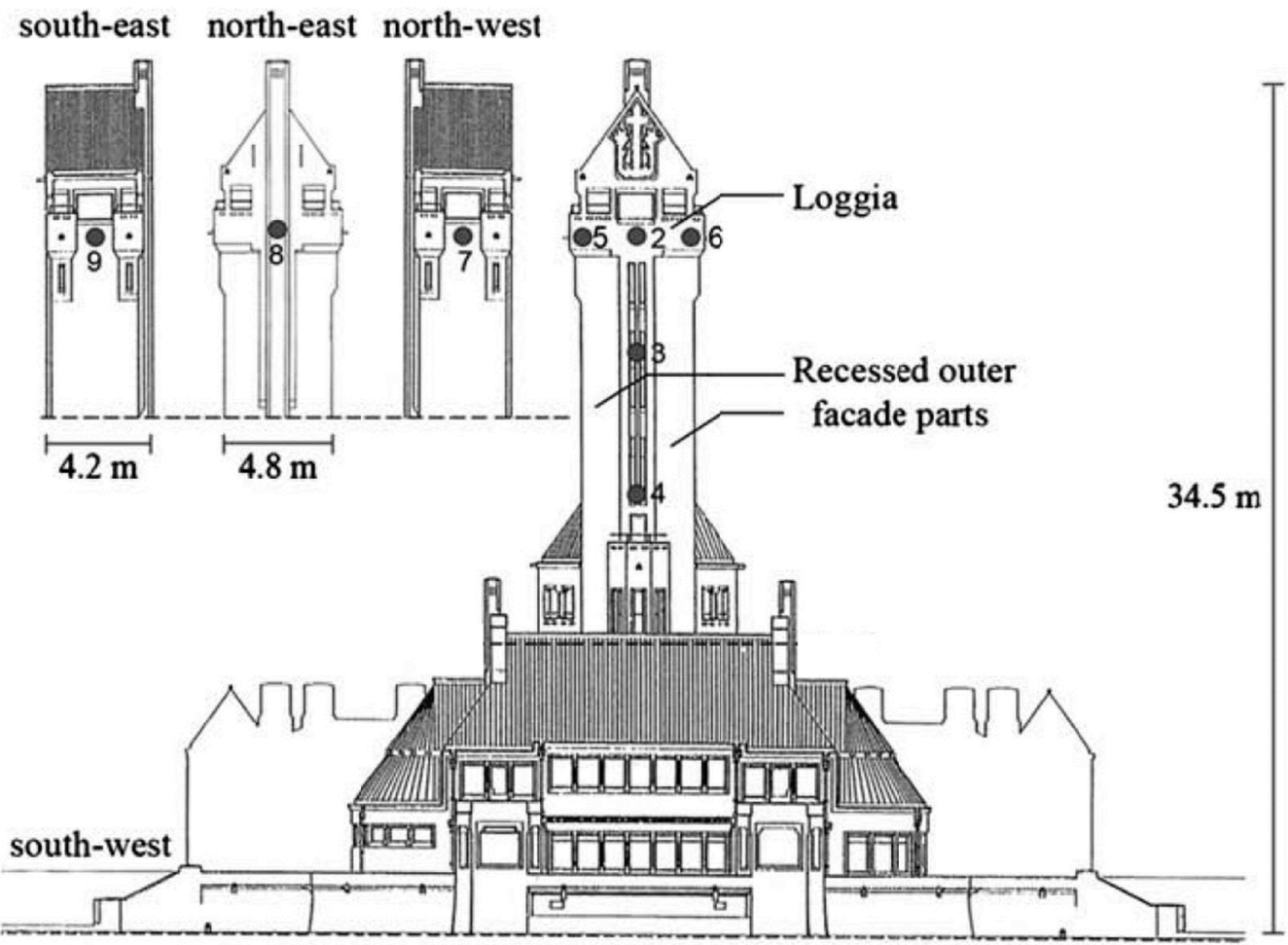

Fig. 2. Hunting Lodge St. Hubertus. Building dimensions and positions of wind-driven rain gauges on the tower by Briggen et al. [25]. 


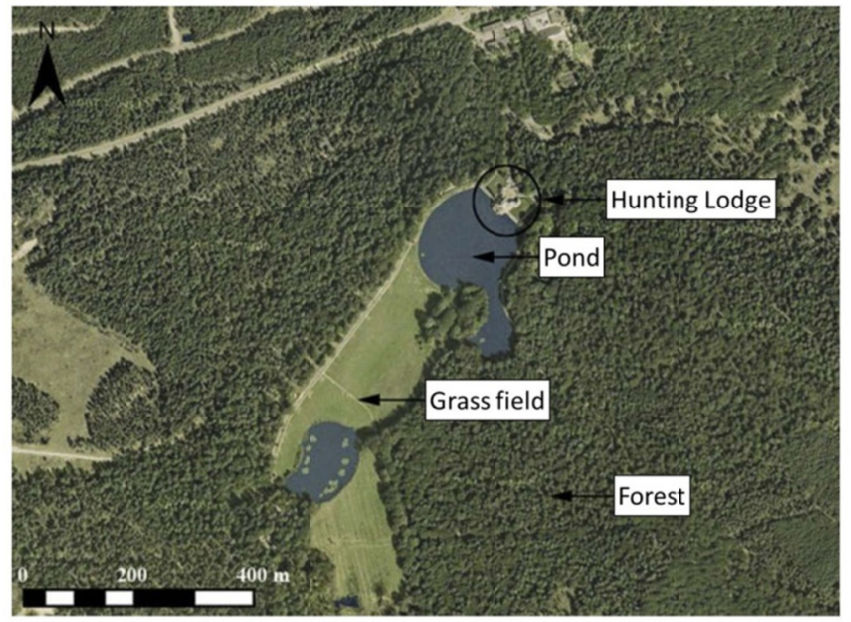

Fig. 3. Aerial view of the topography surrounding the Hunting Lodge (from [25]). 
a)

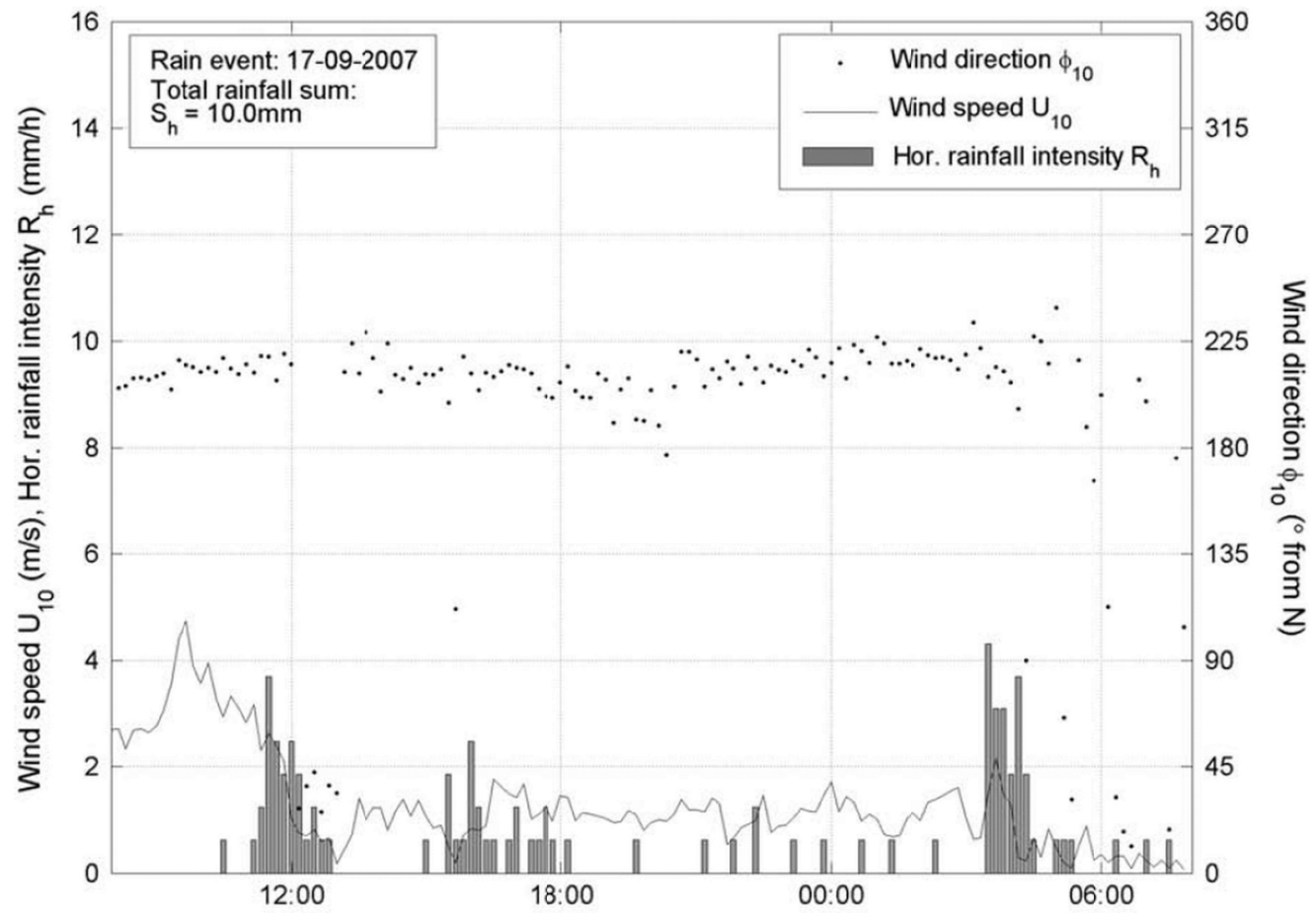

b)

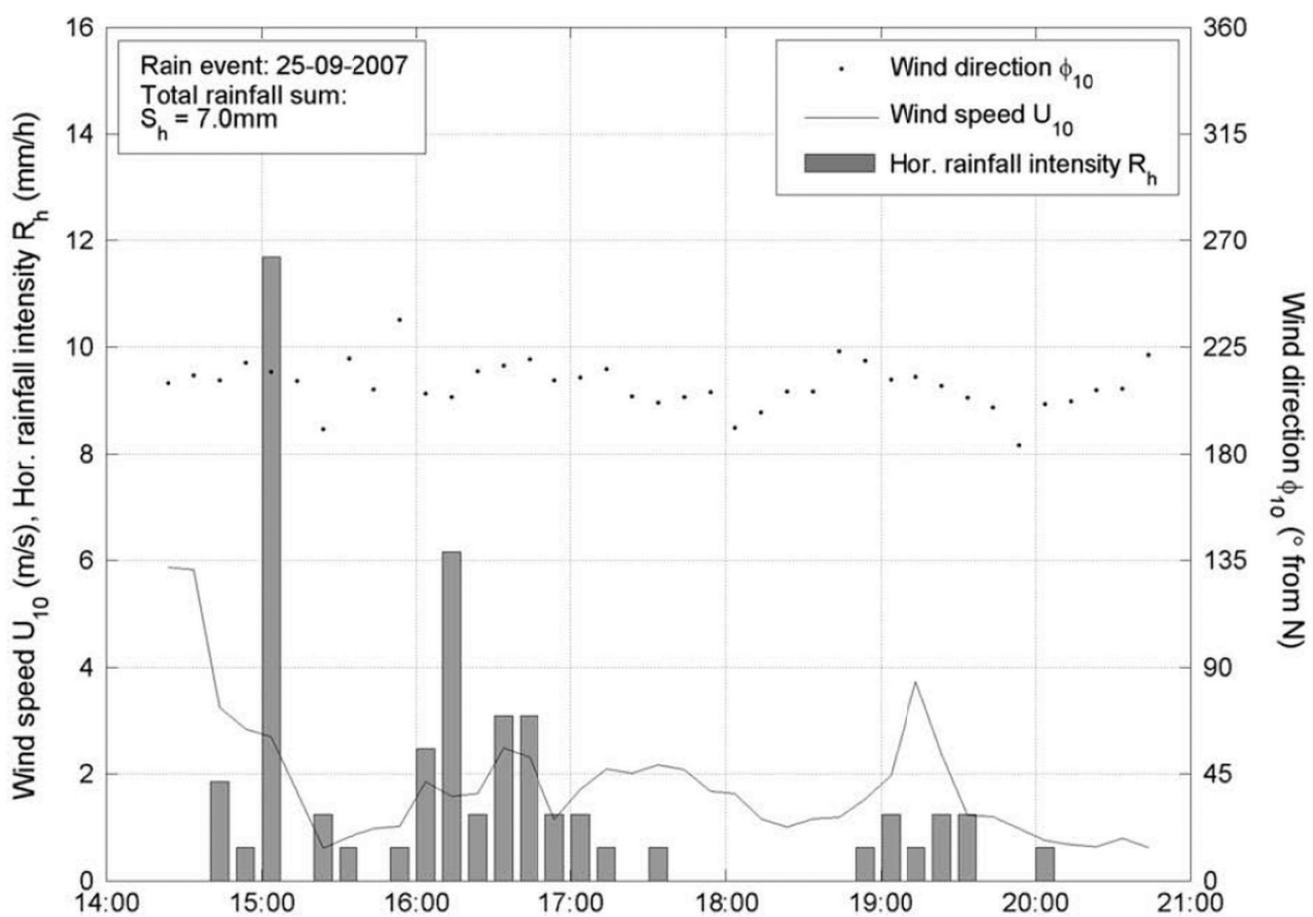

Fig. 4. Record of the meteorological data for the rain event on: a) September $17^{\text {th }}, 2007$, b) September $25^{\text {th }}, 2007$ by Briggen et al. [25]. 


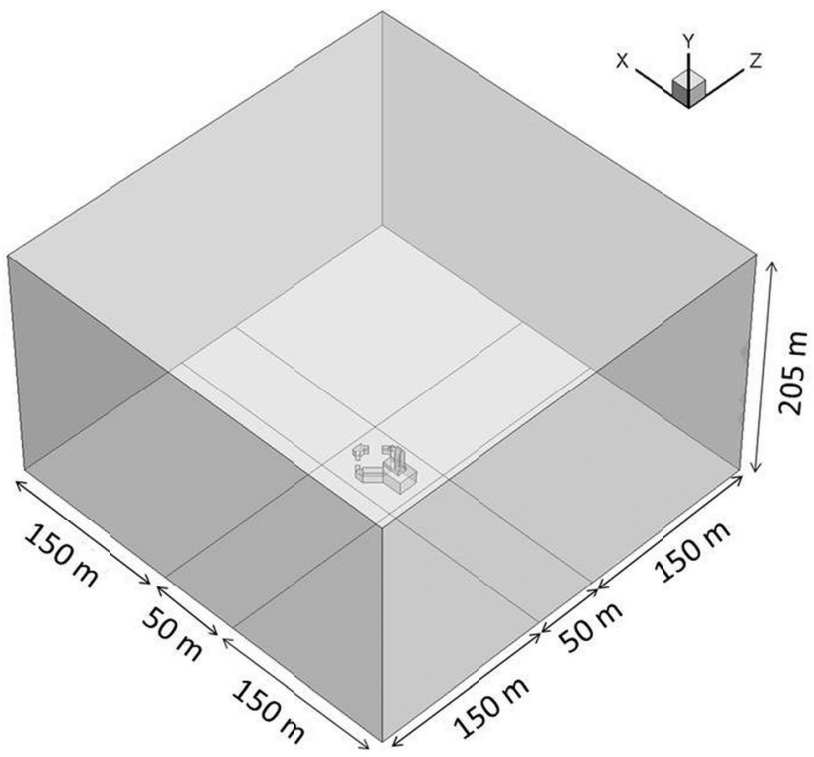

Fig. 5. Computational domain.

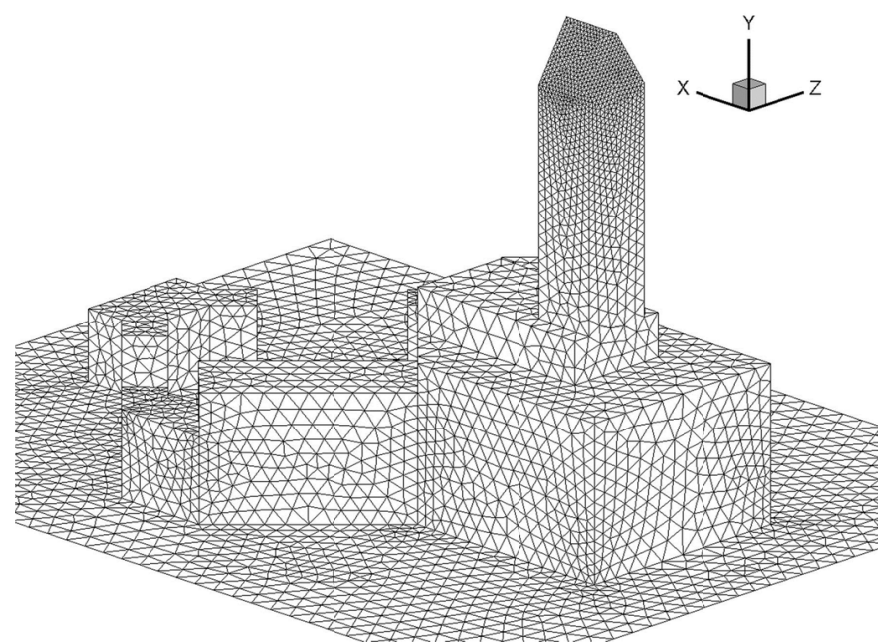

Fig. 6. Computational grid on building and ground surfaces. 


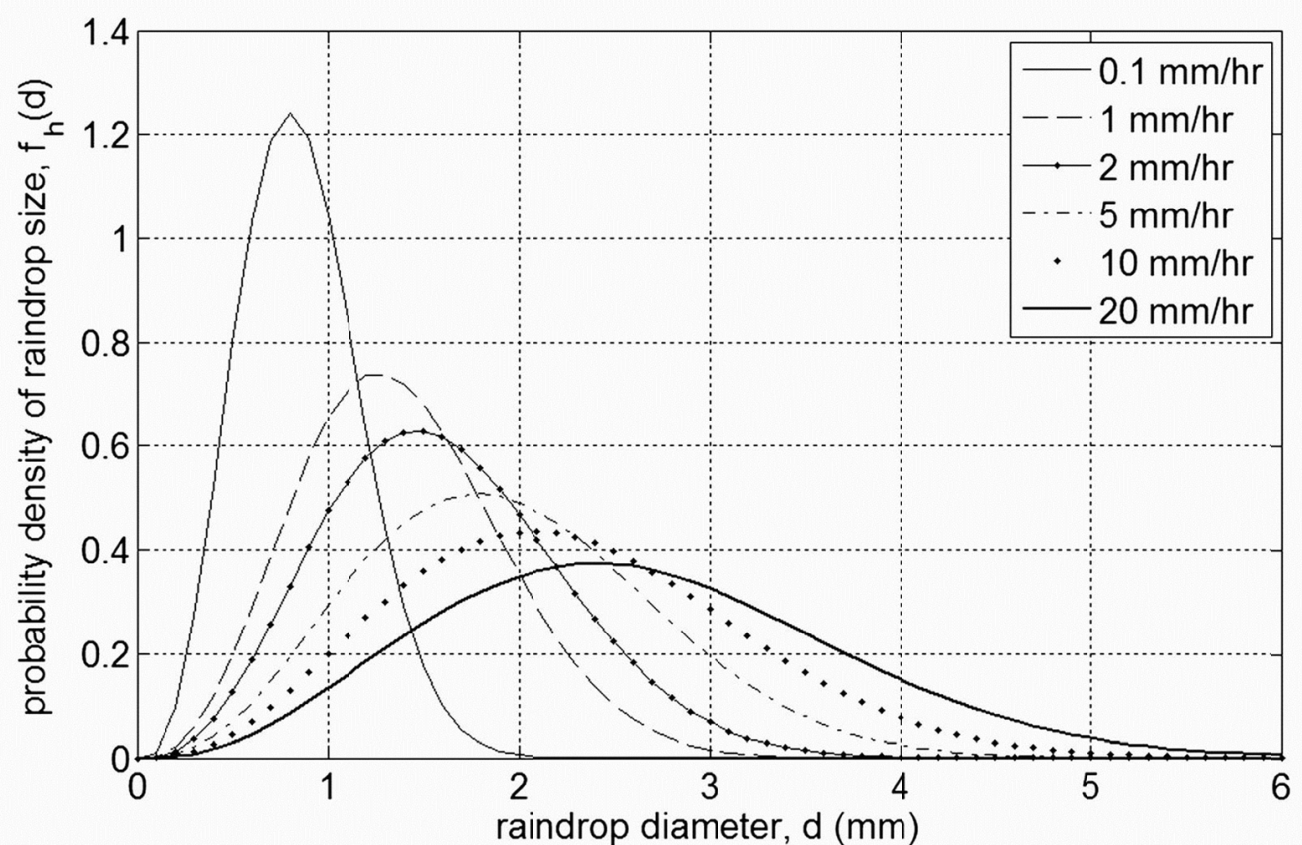

Fig. 7. Raindrop size distribution through a horizontal plane with the rainfall intensity as a parameter - calculated from raindrop size distribution in the air according to Best [34].

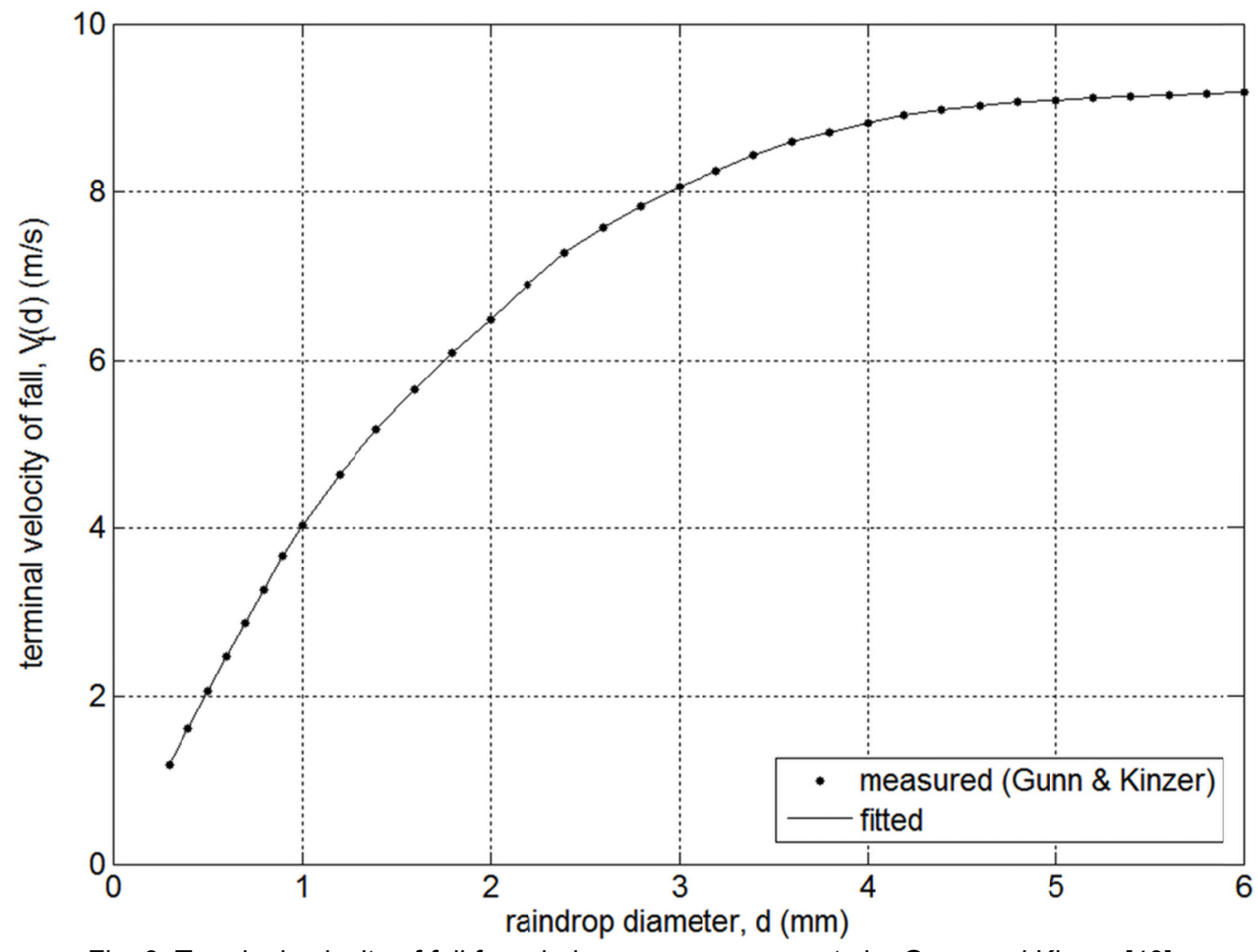

Fig. 8. Terminal velocity of fall for raindrops - measurements by Gunn and Kinzer [40]. 


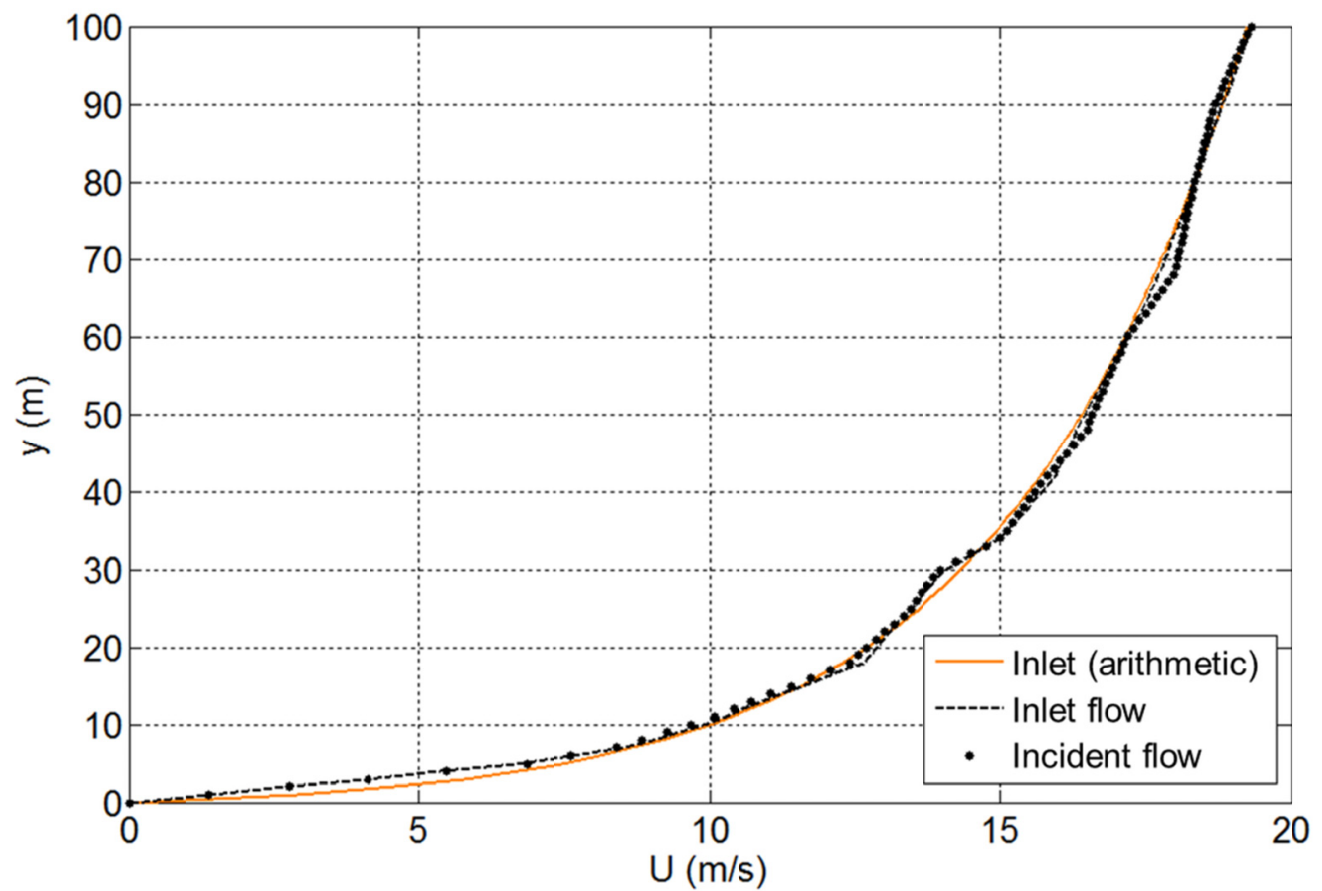

Fig. 9. Horizontal inhomogeneity plot showing the difference between approach flow and incident flow mean wind speed profiles. 
a)

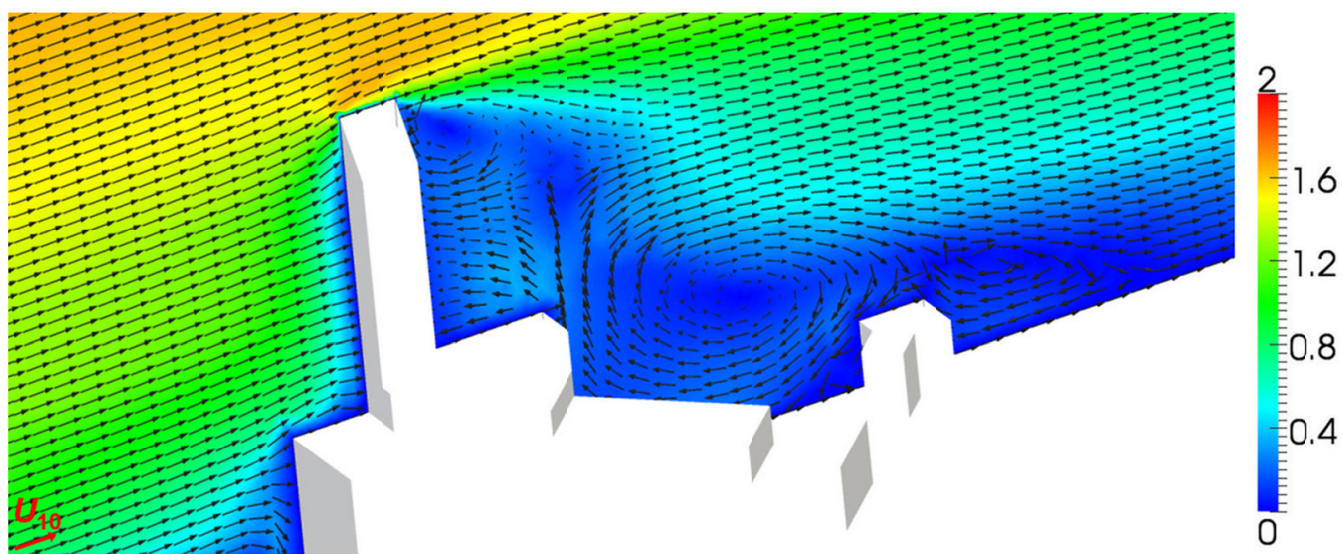

b)

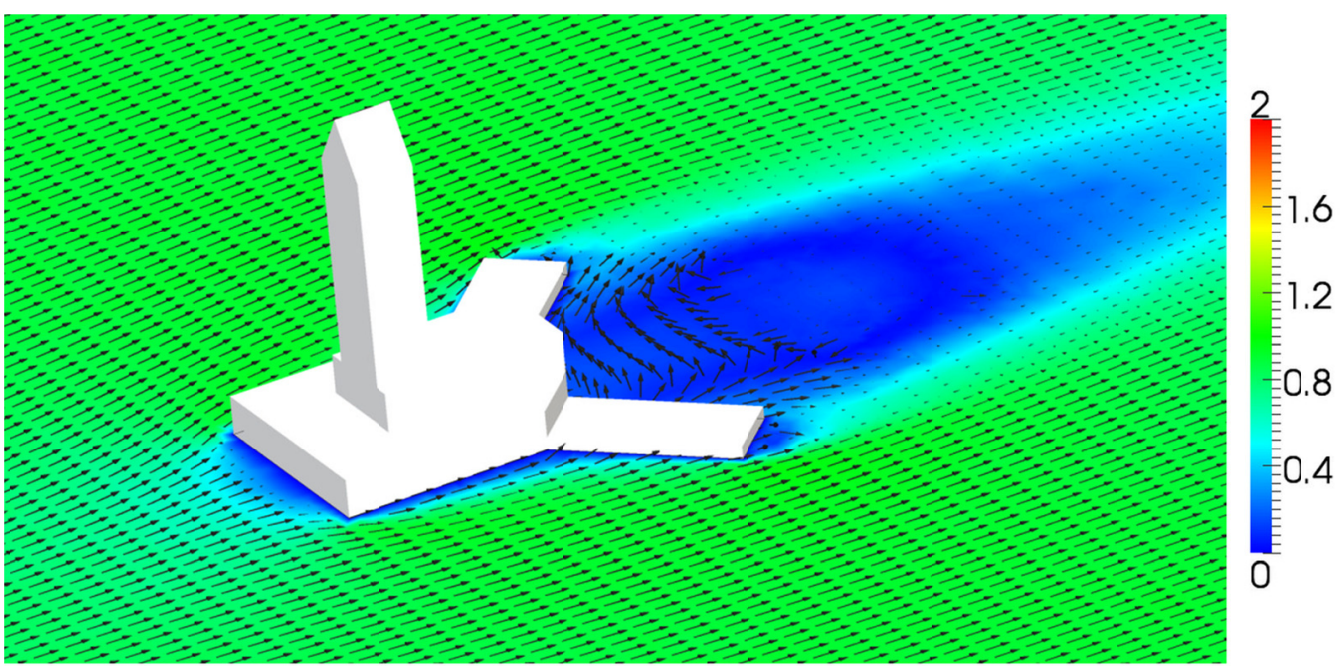

Fig. 10. Wind flow field plot showing mean wind speed and direction at a normalized reference wind speed of $U / U_{10}$ : a) on the vertical mid-plane, b) on the horizontal plane of $y=8 \mathrm{~m}$. 
a)

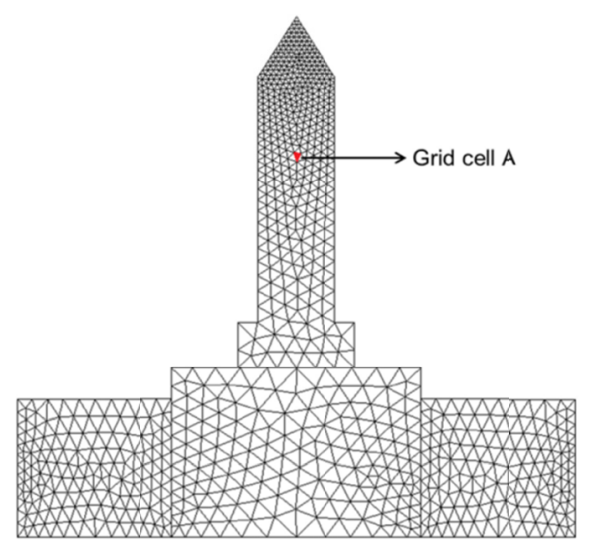

b)

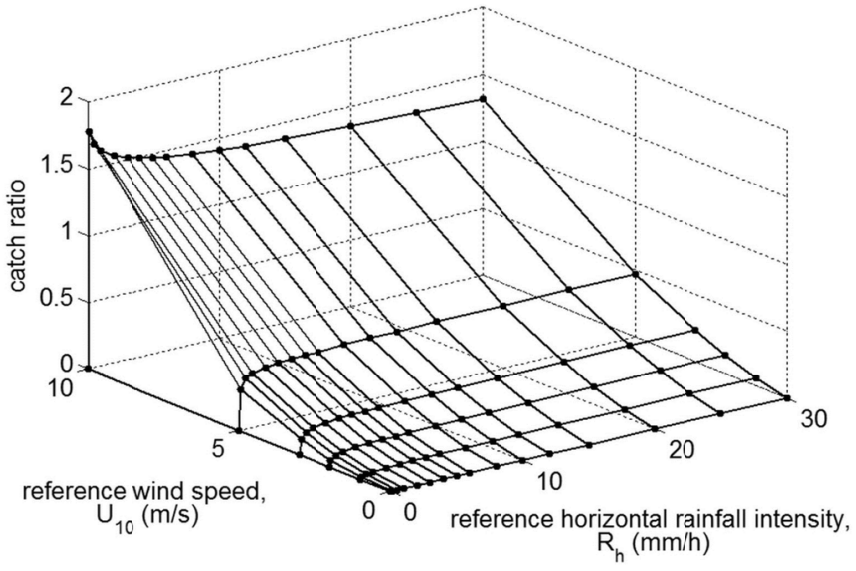

Fig. 11. Catch ratio chart (b) for grid cell A (a) on the windward facade. Linear interpolated using the calculated values (dots) for each couple of reference wind speed and reference horizontal rainfall intensity. 
a)

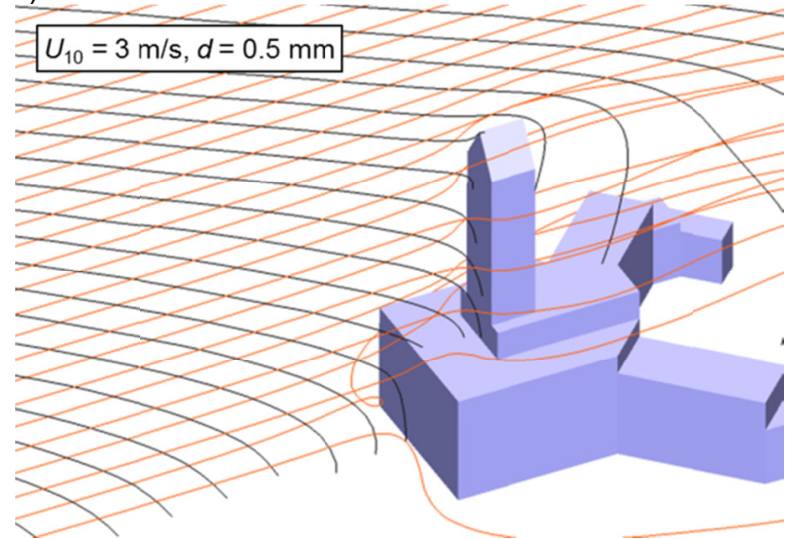

c)

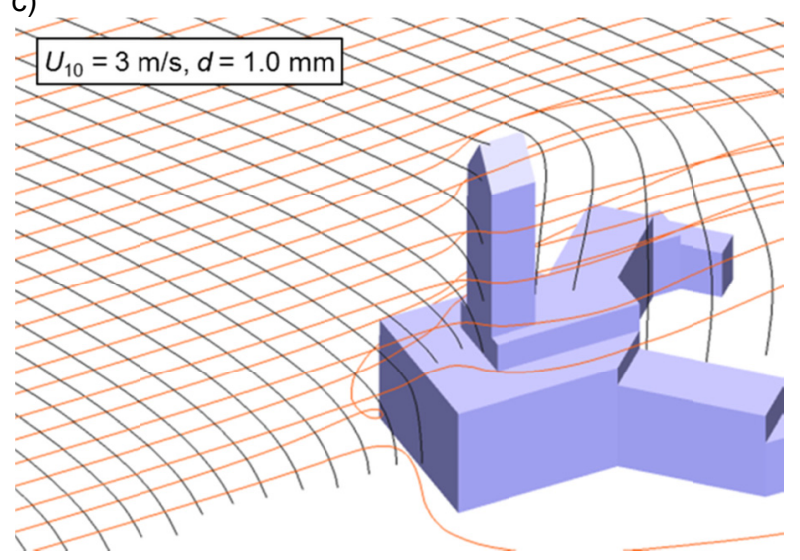

e)

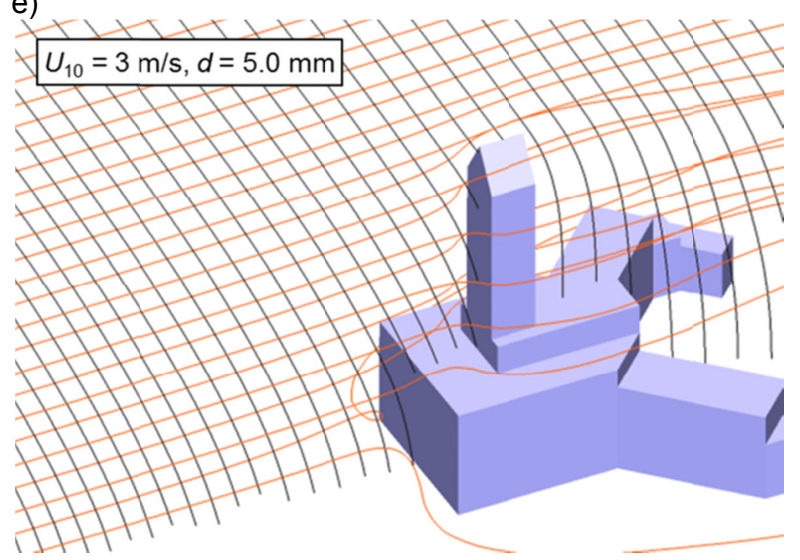

b)

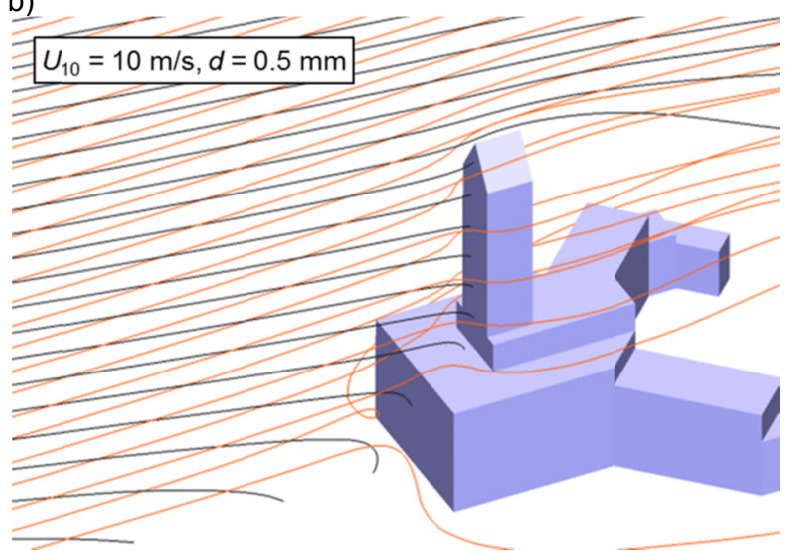

d)

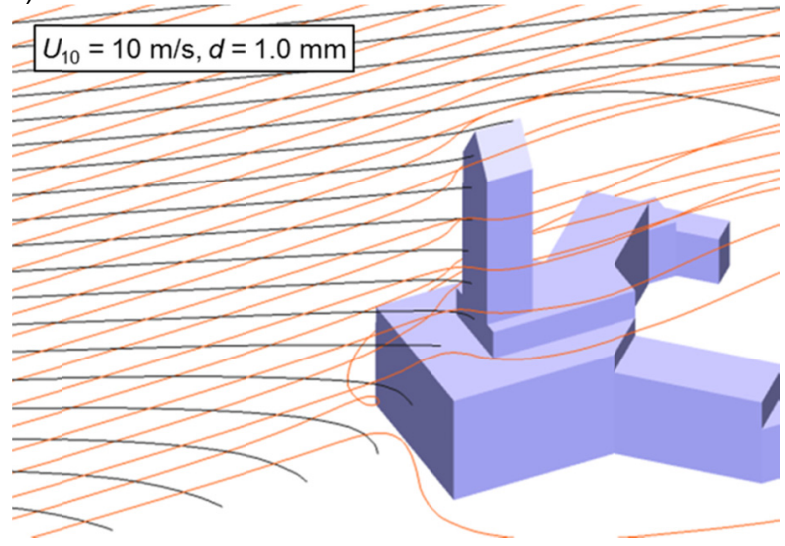

f)

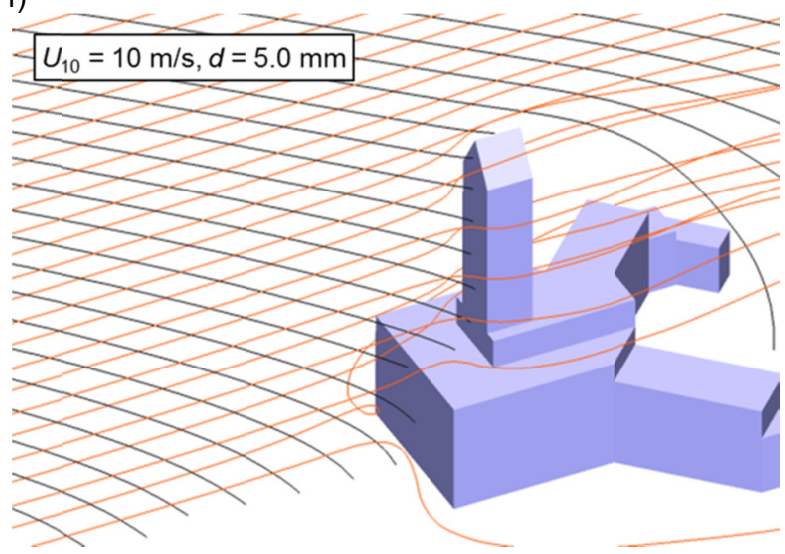

Fig. 12. Streamlines of wind phase (orange -) and rain phase (black -): (a) $U_{10}=3 \mathrm{~m} / \mathrm{s}, d=0.5 \mathrm{~mm}$, (b) $U_{10}=10 \mathrm{~m} / \mathrm{s}$, $d=0.5 \mathrm{~mm}$, (c) $U_{10}=3 \mathrm{~m} / \mathrm{s}, d=1.0 \mathrm{~mm}$, (d) $U_{10}=10 \mathrm{~m} / \mathrm{s}, d=1.0 \mathrm{~mm}$, (e) $U_{10}=3 \mathrm{~m} / \mathrm{s}, d=5.0 \mathrm{~mm}$, (f) $U_{10}=10 \mathrm{~m} / \mathrm{s}, d$ $=5.0 \mathrm{~mm}$. 
a)

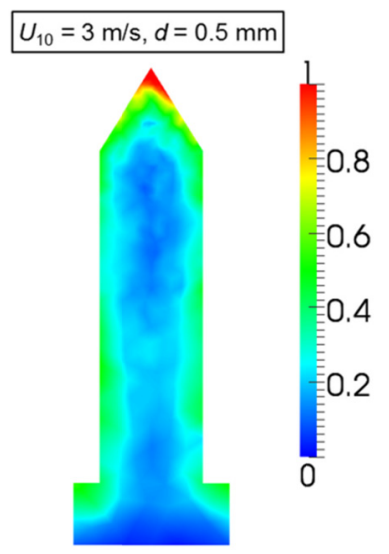

c)

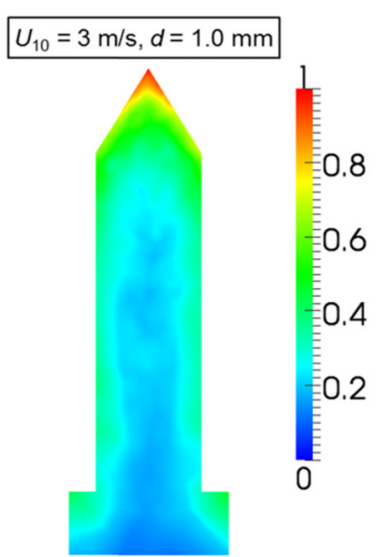

e)

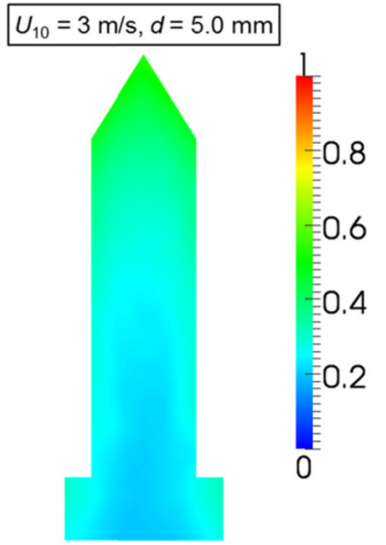

b)

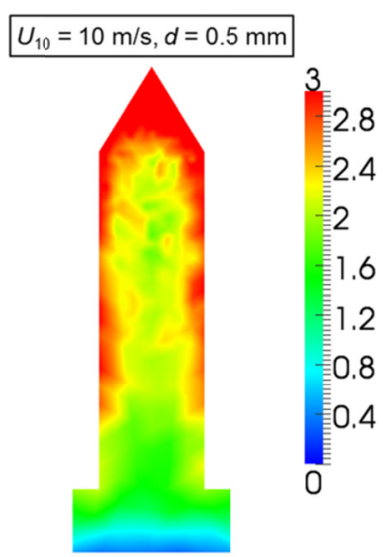

d)

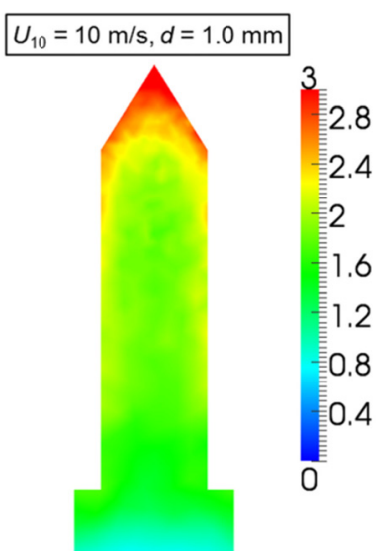

f)

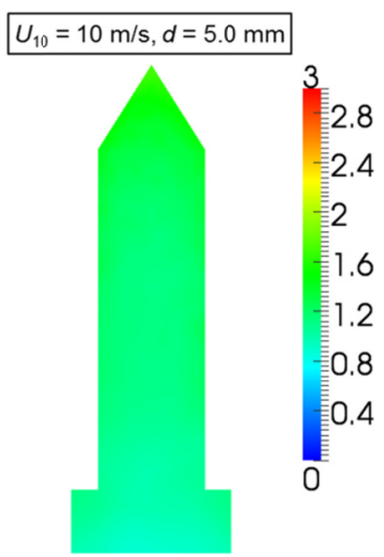

Fig. 13. Specific catch ratio plots on the front facade of the tower: (a) $U_{10}=3 \mathrm{~m} / \mathrm{s}, d=0.5 \mathrm{~mm}$, (b) $U_{10}=10 \mathrm{~m} / \mathrm{s}, d=$ $0.5 \mathrm{~mm}$, (c) $U_{10}=3 \mathrm{~m} / \mathrm{s}, d=1.0 \mathrm{~mm}$, (d) $U_{10}=10 \mathrm{~m} / \mathrm{s}, d=1.0 \mathrm{~mm}$, (e) $U_{10}=3 \mathrm{~m} / \mathrm{s}, d=5.0 \mathrm{~mm}$, (f) $U_{10}=10 \mathrm{~m} / \mathrm{s}, d=$ $5.0 \mathrm{~mm}$. 
a)

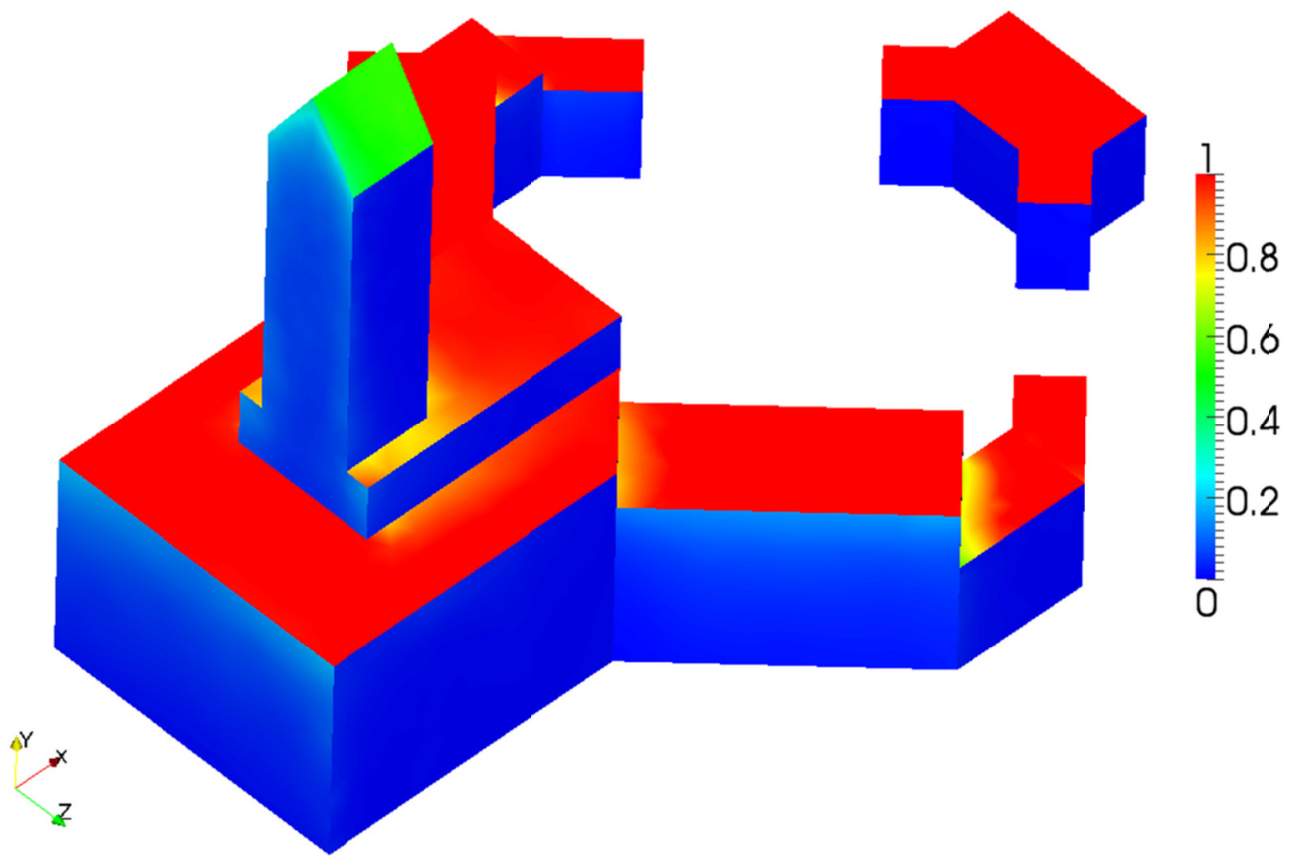

b)

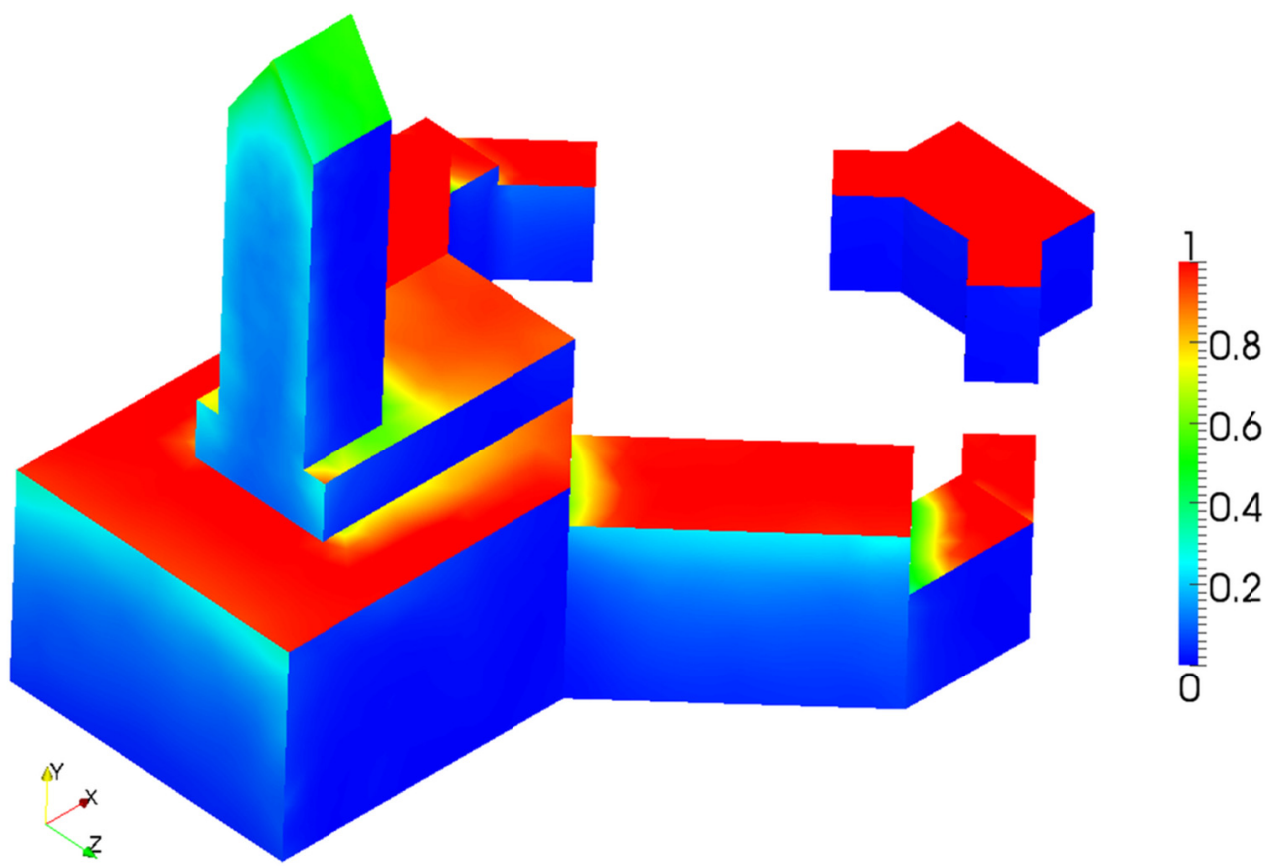

Fig. 14. Catch ratio distribution on the whole building after the rain event on: a) September $17^{\text {th }}, 2007$, b) September $25^{\text {th }}, 2007$. 
a)

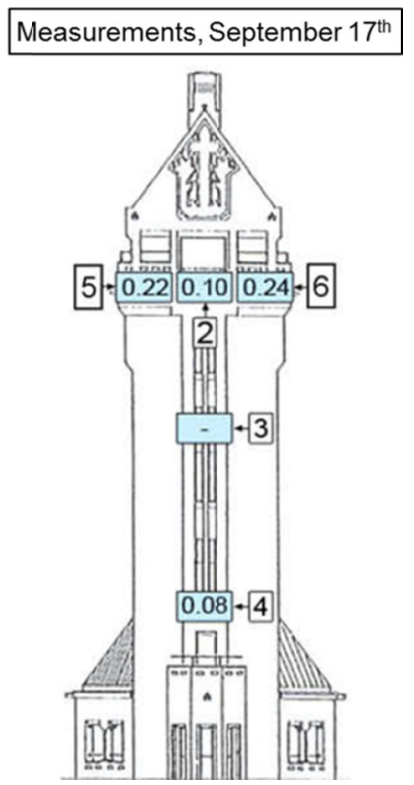

d)

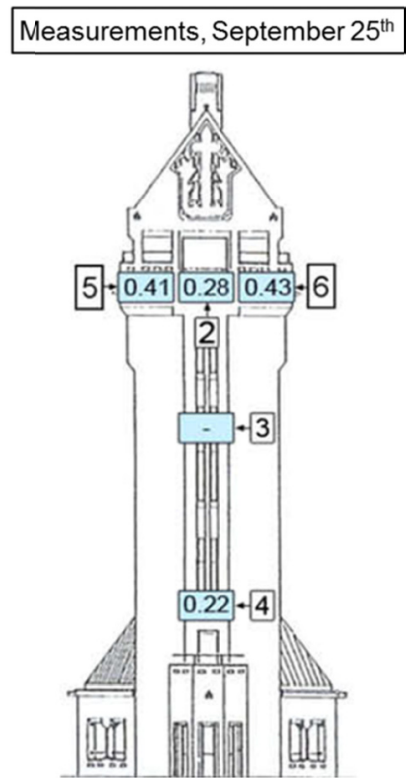

b)

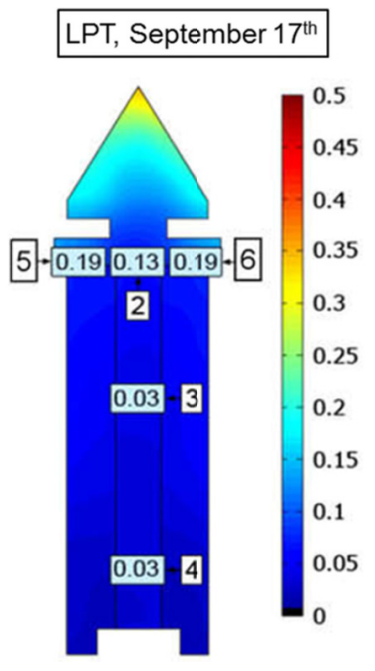

e)

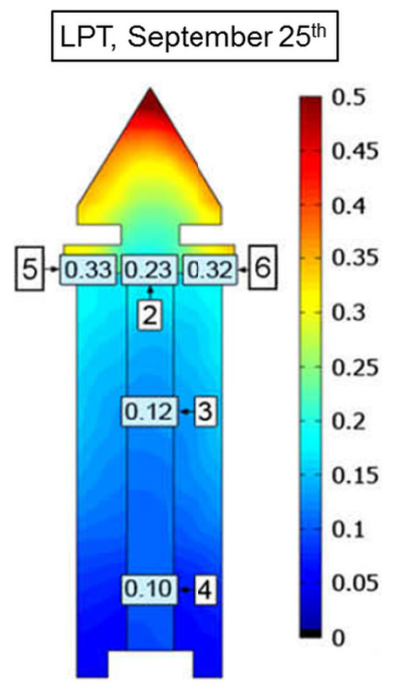

c)

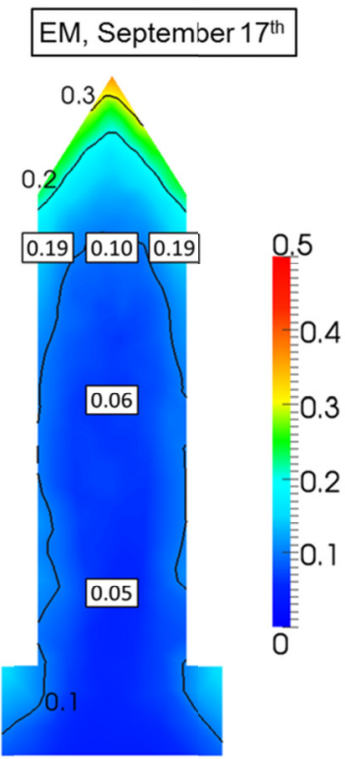

f)

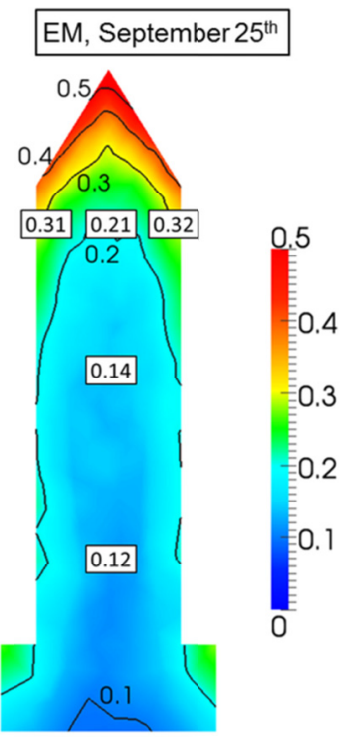

Fig. 15. Catch ratio distribution with EM model compared to the existing measurements data [25] and numerical data [25] on the front facade of the tower after the rain events on: a-c) September $17^{\text {th }}, 2007, d-f$ ) September $25^{\text {th }}, 2007$. 
Table 1. Boundary conditions and parameters for the rain phase

\begin{tabular}{|c|c|c|}
\hline Boundary & Type & Parameters \\
\hline Inlet & $\begin{array}{l}\text { Phase velocity } \\
\text { Phase volumetric ratio }\end{array}$ & $\begin{array}{l}u_{k, x}=u_{x}, u_{k, z}=u_{z}, u_{k, y}=-V_{t}(d) \\
\alpha_{k}=\left(R_{h} \cdot f_{h}\left(R_{h}, d\right)\right) / V_{t}(d)\end{array}$ \\
\hline Outlet & Outlet & $\begin{cases}\frac{\delta \alpha_{k}}{\delta n}=0, \frac{\delta \overrightarrow{u_{k}}}{\delta n}=0 & \text { for } \vec{n} \overrightarrow{u_{k}} \geq 0 \\
\alpha_{k}=0, \overrightarrow{u_{k}}=0 & \text { for } \vec{n} \overrightarrow{u_{k}}<0\end{cases}$ \\
\hline Ground & Outlet & $\begin{cases}\frac{\delta \alpha_{k}}{\delta n}=0, \frac{\delta \overrightarrow{u_{k}}}{\delta n}=0 & \text { for } \vec{n} \overrightarrow{u_{k}} \geq 0 \\
\alpha_{k}=0, \overrightarrow{u_{k}}=0 & \text { for } \vec{n} \overrightarrow{u_{k}}<0\end{cases}$ \\
\hline Building & Outlet & $\begin{cases}\frac{\delta \alpha_{k}}{\delta n}=0, \frac{\delta \overrightarrow{u_{k}}}{\delta n}=0 & \text { for } \vec{n} \overrightarrow{u_{k}} \geq 0 \\
\alpha_{k}=0, \overrightarrow{u_{k}}=0 & \text { for } \vec{n} \overrightarrow{u_{k}}<0\end{cases}$ \\
\hline Top & $\begin{array}{l}\text { Phase velocity } \\
\text { Phase volumetric ratio }\end{array}$ & $\begin{array}{l}u_{k, x}=u_{x}, u_{k, z}=u_{z}, u_{k, y}=-V_{t}(d) \\
\alpha_{k}=\left(R_{h} \cdot f_{h}\left(R_{h}, d\right)\right) / V_{t}(d)\end{array}$ \\
\hline Side & Symmetry & \\
\hline
\end{tabular}

Table 2. Comparison of catch ratio values for the rain event on September 17 ${ }^{\text {th }}, 2007$ (Fig. 4(a))

\begin{tabular}{lccccc}
\hline WDR gauge number & 2 & 3 & 4 & 5 & 6 \\
\hline Measurements [25] & 0.10 & - & 0.08 & 0.22 & 0.24 \\
Numerical results, LPT [25] & 0.13 & 0.03 & 0.03 & 0.19 & 0.19 \\
Numerical results, EMM & 0.10 & 0.06 & 0.05 & 0.19 & 0.19 \\
\hline
\end{tabular}

Table 3. Comparison of catch ratio values for the rain event on September $25^{\text {th }}, 2007$ (Fig. 4(b))

\begin{tabular}{lccccc}
\hline WDR gauge number & 2 & 3 & 4 & 5 & 6 \\
\hline Measurements [25] & 0.28 & - & 0.22 & 0.41 & 0.43 \\
Numerical results, LPT [25] & 0.23 & 0.12 & 0.10 & 0.33 & 0.32 \\
Numerical results, EMM & 0.21 & 0.14 & 0.12 & 0.31 & 0.32 \\
\hline
\end{tabular}




\section{Nomenclature}

\begin{tabular}{|c|c|}
\hline$C_{d}$ & Drag coefficient \\
\hline$C_{s}$ & Roughness constant \\
\hline$C_{\mu}, C_{1 \varepsilon}, C_{2 \varepsilon}$ & Constants in k- $\varepsilon$ turbulence model \\
\hline$d$ & Raindrop diameter \\
\hline$f_{h}(d)$ & Probability density function of raindrop size falling through a horizontal plane \\
\hline$g$ & Gravitational acceleration \\
\hline$G_{k}$ & Generation of turbulent kinetic energy due to mean velocity gradients \\
\hline$I_{u}$ & Turbulence intensity \\
\hline$k$ & Turbulent kinetic energy \\
\hline$k_{s}$ & Physical roughness height \\
\hline$L, B, H$ & Length, width, and height of the computational domain \\
\hline$\vec{n}$ & Normal vector \\
\hline$R e_{R}$ & Relative Reynolds number \\
\hline$R_{h}$ & Horizontal rainfall intensity \\
\hline$R_{w d r}$ & Wind-driven rain intensity \\
\hline$S_{h}$ & Horizontal rainfall amount \\
\hline$u_{A B L}^{*}$ & Friction velocity \\
\hline$U_{10}$ & Reference wind speed at $10 \mathrm{~m}$ height in the upstream undisturbed flow \\
\hline$U$ & Mean streamwise wind speed \\
\hline$\vec{u}$ & Wind phase velocity vector \\
\hline $\overrightarrow{u_{k}}$ & Rain phase velocity vector \\
\hline$\left|V_{n}(k)\right|$ & Velocity magnitude of $k^{\text {th }}$ rain phase in the direction normal to the building facade \\
\hline$V_{t}$ & Terminal velocity of fall \\
\hline$y$ & Height coordinate \\
\hline$y_{0}$ & Aerodynamic roughness length \\
\hline$\alpha_{k}$ & Volume fraction of $k^{\text {th }}$ rain phase \\
\hline$\varepsilon$ & Turbulence dissipation rate \\
\hline$\eta_{d}$ & Specific catch ratio \\
\hline$\eta$ & Catch ratio \\
\hline$\mu$ & Dynamic viscosity of air \\
\hline$\mu_{t}$ & Turbulent viscosity of air \\
\hline$K$ & von Karman constant \\
\hline$\rho_{a}$ & Density of air \\
\hline$\rho_{w}$ & Density of water \\
\hline$\sigma_{\varepsilon}$ & Turbulent Prandtl number for $\varepsilon$ \\
\hline$\sigma_{k}$ & Turbulent Prandtl number for $\mathrm{k}$ \\
\hline $\mathrm{ABL}$ & Atmospheric Boundary Layer \\
\hline CFD & Computational Fluid Dynamics \\
\hline DES & Detached Eddy Simulation \\
\hline BE-HAM & Building Envelope - Heat, Air, Moisture \\
\hline EM & Eulerian Multiphase Model \\
\hline LES & Large Eddy Simulation \\
\hline LPT & Lagrangian Particle Tracking \\
\hline RANS & Reynolds Averaged Navier Stokes \\
\hline WDR & Wind-Driven Rain \\
\hline
\end{tabular}

